OPEN ACCESS

Edited by:

Manuel González-Guerrero, Universidad Politécnica de Madrid

(UPM), Spain

Reviewed by:

Crysten Elizabeth Blaby-Haas,

Brookhaven National Laboratory

(DOE), United States

Marc Hanikenne,

University of Liège, Belgium

*Correspondence:

Lola Peñarrubia

penarrub@uv.es

tPresent address:

Nuria Andrés-Colás,

Departamento de Biotecnología, Universitat Politècnica de València,

Valencia, Spain

Specialty section:

This article was submitted to

Plant Nutrition,

a section of the journal

Frontiers in Plant Science

Received: 28 March 2018 Accepted: 08 June 2018

Published: 03 July 2018

Citation:

Andrés-Colás N, Carrió-Seguí A,

Abdel-Ghany SE, Pilon $M$ and

Peñarrubia $L$ (2018) Expression of the Intracellular COPT3-Mediated Cu

Transport is Temporally Regulated by the TCP16 Transcription Factor.

Front. Plant Sci. 9:910

doi: 10.3389/fpls.2018.00910

\section{Expression of the Intracellular COPT3-Mediated Cu Transport Is Temporally Regulated by the TCP16 Transcription Factor}

\author{
Nuria Andrés-Colás ${ }^{1+}$, Angela Carrió-Seguí ${ }^{1}$, Salah E. Abdel-Ghany ${ }^{2}$, Marinus Pilon $^{2}$ and \\ Lola Peñarrubia ${ }^{1 *}$
}

${ }^{1}$ Departament de Bioquímica i Biologia Molecular, Estructura de Recerca Interdisciplinar en Biotecnologia i Biomedicina, Universitat de València, Valencia, Spain, ${ }^{2}$ Department of Biology, Colorado State University, Fort Collins, CO, United States

Copper is an essential element in plants. When scarce, copper is acquired from extracellular environment or remobilized from intracellular sites, through members of the high affinity copper transporters family COPT located at the plasma membrane and internal membrane, respectively. Here, we show that COPT3 is an intracellular copper transporter, located at a compartment of the secretory pathway, that is mainly expressed in pollen grains and vascular bundles. Contrary to the COPT1 plasma membrane member, the expression of the internal COPT3 membrane transporter was higher at $12 \mathrm{~h}$ than at $\mathrm{O} \mathrm{h}$ of a neutral photoperiod day under copper deficiency. The screening of a library of conditionally overexpressed transcription factors implicated members of the TCP family in the COPT3 differential temporal expression pattern. Particularly, in vitro, TCP16 was found to bind to the COPT3 promoter and down-regulated its expression. Accordingly, TCP16 was mainly expressed at $0 \mathrm{~h}$ under copper deficiency and induced at $12 \mathrm{~h}$ by copper excess. Moreover, TCP16 overexpression resulted in increased sensitivity to copper deficiency, whereas the tcp16 mutant was sensitive to copper excess. Both copper content and the expression of particular copper status markers were altered in plants with modified levels of TCP16. Consistent with TCP16 affecting pollen development, the lack of COPT3 function led to altered pollen morphology. Furthermore, analysis of copt3 and COPT3 overexpressing plants revealed that COPT3 function exerted a negative effect on TCP16 expression. Taken together, these results suggest a differential daily regulation of copper uptake depending on the external and internal copper pools, in which TCP16 inhibits copper remobilization at dawn through repression of intracellular transporters.

Keywords: copper transport, COPT3, heavy metals, TCP16, transcriptional regulation

\section{INTRODUCTION}

Copper $(\mathrm{Cu})$ is an essential micronutrient for the growth and development of aerobic organisms. Under metal deficiency, $\mathrm{Cu}^{+}$is incorporated through high affinity $\underline{\mathrm{COP} p e r}$ Transporters, denoted COPTs in plants (Kampfenkel et al., 1995; Sancenón et al., 2003; Puig, 2014; Peñarrubia et al., 2015) and referred to as CTR (SLC31) in other organisms (Kim et al., 2013). In Arabidopsis thaliana, the COPT family can be divided into two subfamilies: the plasma membrane members 
COPT1, COPT2, and COPT6 (pmCOPT), which are transcriptionally induced under $\mathrm{Cu}$ deficiency (Sancenón et al., 2004; Garcia-Molina et al., 2013; Perea-García et al., 2013), and the members located in internal membranes COPT3 and COPT5 (imCOPT), which are not clearly induced by $\mathrm{Cu}$ deficiency (Sancenón et al., 2003; Garcia-Molina et al., 2011; Klaumann et al., 2011). This subdivision might distinguish at least two $\mathrm{Cu}^{+}$sources in the cells (external and internal), differentially mobilized based on the type of COPT activated.

The transcriptional response to $\mathrm{Cu}$ deficiency is mainly orchestrated by the transcription factor (TF) SQUAMOSA PROMOTER BINDING PROTEIN-LIKE7 (SPL7) through binding to GTAC motifs in the promoters of target genes, such as pmCOPT (Yamasaki et al., 2009; Bernal et al., 2012). Thus, pmCOPT-mediated cytosolic $\mathrm{Cu}^{+}$uptake from the extracellular environment is highly increased by SPL7 under $\mathrm{Cu}$ deficiency. It has been suggested that the SPL7-mediated auto-regulatory effect of $\mathrm{Cu}$ on $p m C O P T$ expression could establish a feedback loop responsible for cyclic expression, peaking at dawn (Andrés-Colás et al., 2010; Peñarrubia et al., 2010). Deregulated $\mathrm{Cu}^{+}$uptake in COPT-overexpressing plants causes abnormal development in the absence of environmental cycles (Andrés-Colás et al., 2010; Perea-García et al., 2016a,b). Furthermore, the observed interaction between SPL7 and ELONGATED HYPOCOTYL5 (HY5) underscores a connection between $\mathrm{Cu}$ homeostasis and light (Zhang et al., 2014).

In yeast, it has been shown that, due to the $\mathrm{Cu}^{+}$ toxicity, practically no free $\mathrm{Cu}^{+}$is found in the cytosolic compartment (Rae et al., 1999). Therefore, pmCOPT-mediated $\mathrm{Cu}^{+}$uptake is probably coupled to cupro-chaperone-mediated delivery to different protein targets, among them the P-type ATPase RESPONSIVE-TO-ANTAGONIST1 (RAN1) located at the endoplasmic reticulum (ER) where it pumps $\mathrm{Cu}^{+}$into the lumen (Hirayama et al., 1999). SPL7 presents an operative transmembrane domain that allow his localization at the endomembrane system, most likely the ER. During ER stress, as a result of $\mathrm{Cu}$ deficiency, SPL7 localizes in the nucleus to modulate the $\mathrm{Cu}$ deficiency responses, after activation by proteolytic cleavage. In this sense, SPL7 could function as a double $\mathrm{Cu}$ sensor in both the nucleo-cytoplasm and the ER lumen (Garcia-Molina et al., 2014).

With regard to the imCOPT-mediated $\mathrm{Cu}^{+}$transport from internal sources, COPT5 plays an important role in the plant response to severe environmental $\mathrm{Cu}$ scarcity (GarciaMolina et al., 2011; Klaumann et al., 2011). COPT5 functions in remobilizing $\mathrm{Cu}$ from prevacuolar vesicles, which could act as internal stores or recycling vesicles to provide the metal to key $\mathrm{Cu}$-dependent processes such as photosynthesis (Garcia-Molina et al., 2011; Klaumann et al., 2011; CarrióSeguí et al., 2015). Little is known about the function of COPT3. COPT3 has been classified as a member of the imCOPT subfamily based on its partial complementation of the respiratory and $\mathrm{Cu}$ transport defect exhibited by a $\operatorname{ctr} 1 \Delta \operatorname{ctr} 3 \Delta$ yeast mutant (Sancenón et al., 2003; Garcia-Molina et al., 2013). Apparently, imCOPT expression is not affected by $\mathrm{Cu}$ and temporal factors modulating imCOPT expression remain unexplored.
The TCP (named after TEOSINTE BRANCHED 1, CYCLOIDEA and PROLIFERATING CELL FACTOR 1) protein family precisely orchestrates spatial and temporal plant responses to both environmental and endogenous factors (Martín-Trillo and Cubas, 2010; Kieffer et al., 2011; Li, 2015; Danisman, 2016; Dhaka et al., 2017). The TCP family is constituted by plant-specific TFs that share a conserved non-canonical basic helix-loop-helix (bHLH) DNA binding domain, termed TCP domain (Cubas et al., 1999). The TCP members, are grouped into two subfamilies, based on the TCP domain structure and their roles (Cubas et al., 1999). These subfamilies are denoted as class I or PROLIFERATING CELL FACTOR (PCF) and class II, which is divided in CINCINNATA (CIN) and CYCLOIDEA (CYC)/(TEOSINTE BRANCHED 1) TB1 proteins. TCPs bind cis-acting regulatory elements (CAREs) known as site II, in the promoter regions of various genes. CAREs come in two classes: class I (GTGGGNCC) and class II (GTGGNCCC), which have different but similar binding preferences (Kosugi and Ohashi, 2002; Viola et al., 2012). The peculiar class I member TCP16 is an exception with preference for class II binding site since it contains Asp instead of Gly at a key discriminatory position (Uberti-Manassero et al., 2016).

A key mechanism underlying temporal control is the circadian clock. Among the central Arabidopsis clock components are the TFs CIRCADIAN CLOCK-ASSOCIATED 1 (CCA1) and LATE ELONGATED HYPOCOTYL (LHY) (for a review, see Nohales and Kay, 2016). Some TCP members interact with different components of the core circadian clock as shown in both yeast two-hybrid and protein-protein interaction assays (Giraud et al., 2010), which indicates that the TCP family is intricately linked to circadian regulation of gene expression in Arabidopsis. TCP21, termed CHE (for CCA1 Hiking Expedition), binds TOC1 (timing of $\mathrm{CAB}$ expression 1), which provides an explanation of how TOC1 can regulate expression of CCA1, as TOC1 lacks a DNA binding domain (Pruneda-Paz et al., 2009). Moreover, the concomitant binding of TCP20/TCP22 and LWD1 (LIGHT-REGULATED WD1) to the CCA1 promoter activates its expression at dawn (Wu et al., 2016). Furthermore, TCPs appear to link the diurnal changes in mitochondrial function, particularly in genes encoding components of the oxidative phosphorylation machinery, with transcriptional changes that are regulated and integrated with the central clock function. This provides a molecular link between cellular and organelle metabolic activity and the circadian clock in plants (Palatnik et al., 2003; Welchen and Gonzalez, 2006; Giraud et al., 2010; Danisman, 2016).

Other developmental plant process that requires a TCP-mediated precise spatial and temporal control is the regulation of floral organ development, including secondary cell wall thickening necessary to release pollen grains. This developmental program is under the precise control of TCP24, which functions as a negative regulator (Wang et al., 2015). Moreover, the inhibition of the TCP16 function results in abortion of early pollen development (Takeda et al., 2006). In rice, class I TCP genes have been mainly implicated in stress adaptation, such as salinity tolerance (Almeida et al., 2017) or cold stress (Wang et al., 2014). OsTCP19 facilitates abiotic stress 
tolerance by manipulating the abscisic acid (ABA) signaling network (Mukhopadhyay and Tyagi, 2015). The wide crosstalk between TCP and hormones has been recently summarized (Nicolas and Cubas, 2016).

Environmental signals, such as nutrient availability, also lead to TCP-mediated regulation. In this sense, TCP20 and NIN-like proteins (NLP6 and NPL7) are involved in nitrate availability responses (Guan et al., 2014, 2017). This is only an example of the high range of TCPs interactions with other TFs (Bemer et al., 2017). These multiple interactions highlight the central role of TCPs in plant molecular networks that integrate environmental and endogenous processes in plants (Danisman, 2016; Dhaka et al., 2017). Metal availability is a key environmental factor under precise temporal control intricately linked with the circadian clock (Andrés-Colás et al., 2010; Hermans et al., 2010; Chen et al., 2013; Hong et al., 2013; Salomé et al., 2013). In this regard, it has been shown that TCP20 transcriptionally repress the expression of the subgroup Ib of bHLH TFs, previously implicated in iron homeostasis (Wang et al., 2007). Moreover, these TFs are up-regulated in the transition from cell proliferation to cell expansion during sink-source transitions (Andriankaja et al., 2014).

Although the activation of $\mathrm{Cu}^{+}$uptake through the pmCOPT transporters under Cu deficiency by SLP7 is a well-established process (Yamasaki et al., 2009; Bernal et al., 2012), their temporal control, as well as the transcriptional regulation of imCOPTs, COPT3 and COPT5, remain unsolved. In this work, we have identified TCP16 as a TF that, besides SPL7, could participate in $\mathrm{Cu}$ homeostasis via temporal modulation of gene expression in Arabidopsis.

\section{MATERIALS AND METHODS}

\section{Plant Growth Conditions and Treatments}

A. thaliana plants, ecotype $\mathrm{Col} 0$, and the transgenic lines indicated in Supplementary Table SI were grown as previously described (Andrés-Colás et al., 2010). The half-strength Murashige and Skoog ( $1 / 2$ MS) medium was either commercial (Sigma) or prepared in the laboratory as follows: macronutrients $12.5 \mathrm{ml}\left(\mathrm{NH}_{4} \mathrm{NO}_{3} 825 \mathrm{mg} / \mathrm{l}, \mathrm{KNO}_{3} 950 \mathrm{mg} / \mathrm{l}, \mathrm{MgSO}_{4} \cdot 7 \mathrm{H}_{2} \mathrm{O}\right.$ $90.35 \mathrm{mg} / \mathrm{l}, \quad \mathrm{KH}_{2} \mathrm{PO}_{4} 85 \mathrm{mg} / \mathrm{l}$, and $\mathrm{CaCl}_{2} 166.25 \mathrm{mg} / \mathrm{l}$ ), micronutrients $0.5 \mathrm{ml}\left(\mathrm{H}_{3} \mathrm{BO}_{3} 3.1 \mathrm{mg} / \mathrm{l}, \mathrm{MnSO}_{4} \cdot \mathrm{H}_{2} \mathrm{O} 8.45 \mathrm{mg} / \mathrm{l}\right.$, $\mathrm{ZnSO}_{4} \cdot 7 \mathrm{H}_{2} \mathrm{O} \quad 4.3 \mathrm{mg} / \mathrm{l}, \quad \mathrm{NaMoO}_{4} \cdot 2 \mathrm{H}_{2} \mathrm{O} \quad 0.125 \mathrm{mg} / \mathrm{l}$, and $\left.\mathrm{CoCl}_{2} \cdot 6 \mathrm{H}_{2} \mathrm{O} 0.0125 \mathrm{mg} / \mathrm{l}\right)$, Fe-EDTA $2.5 \mathrm{ml}\left(\mathrm{FeSO}_{4} \cdot 7 \mathrm{H}_{2} \mathrm{O}\right.$ $13.9 \mathrm{mg} / \mathrm{l}$ and $\mathrm{Na}_{2}$ EDTA $\left.2 \mathrm{H}_{2} \mathrm{O} \quad 18.63 \mathrm{mg} / \mathrm{l}\right)$, KI $1.1 \mathrm{ml}$ $(0.41 \mathrm{mg} / \mathrm{l})$, in both cases supplemented with MES $0.5 \mathrm{~g} / \mathrm{l}$, sucrose $10 \mathrm{~g} / \mathrm{l}$, agar $8 \mathrm{~g} / \mathrm{l}$, pH 5.7 with $\mathrm{KOH}$. Variable $\mathrm{CuSO}_{4}$ concentrations were added when indicated. Media were supplemented with $100 \mu \mathrm{M}$ BCS for the $\mathrm{Cu}$-deprived media.

A COPT3 promoter (COPT3p), covering 1,248 bp upstream from the start codon, was fused to the uidA (GUS) reporter gene (COPT3p:GUS) by substitution of the CaMV35S promoter in the pBI121 vector. At least two independent transgenic Arabidopsis stable homozygous lines harboring the COPT3p:GUS chimeric construct were obtained and analyzed.
The phenotype of two independent TRANSPLANTA (TPT) TPT TCP16 lines (Coego et al., 2014) was analyzed on $1 / 2$ MS medium with $100 \mu \mathrm{M} \mathrm{BCS}$, with or without $2 \mu \mathrm{M}$ $\beta$-estradiol after germinating on $1 / 2$ MS medium 2 days or for the indicated period, and under long $\left(16 \mathrm{~h}\right.$ light $-23^{\circ} \mathrm{C} / 8 \mathrm{~h}$ dark- $\left.16^{\circ} \mathrm{C}\right)$ or neutral $\left(12 \mathrm{~h}\right.$ light $-23^{\circ} \mathrm{C} / 12 \mathrm{~h}$ dark- $\left.16^{\circ} \mathrm{C}\right)$ photoperiod conditions, as indicated. For the gene expression analysis by RT-qPCR of TPT TCP16 lines, plants were grown directly with 2 $\mu \mathrm{M} \beta$-estradiol. For this expression analysis, one TPT TCP16 line was used and compared to the wild-type. Samples were collected at 0,12 , or $24 \mathrm{~h}$ from plants grown under neutral conditions ( 0 or $24 \mathrm{~h}$, start of light; $12 \mathrm{~h}$, end of light), as indicated.

For the genotyping of the T-DNA insertion lines, plants were self-pollinated and homozygous lines were obtained. PCR (Supplementary Table SIV) or RT-qPCR (Supplementary Table SV) were performed with specific oligonucleotides to genotype or check the loss of expression in the lines, respectively. For the tcp16 mutant, one line was analyzed and compared to the previously obtained TCP16 RNAi line. For the copt3 mutant, one line was analyzed and compared to the COPT3-HA overexpressing line. For the copt 5 mutant, one of the previously characterized lines was used as a control for sensitivity to $\mathrm{Cu}$ deficiency.

\section{Electrophoretic Mobility Shift Assay (EMSA)}

Biotin-labeled and unlabeled oligonucleotides (Supplementary Table SII), including the putative TCP binding motifs of COPT3 and COPT5 promoters, and a fragment of the COPT2 promoter (without TCP binding motifs), were synthetized (VWR) and annealed in TEN buffer $(10 \mathrm{mM}$ Tris Base $\mathrm{pH}$ 7.8, $1 \mathrm{mM}$ EDTA, $0.1 \mathrm{M} \mathrm{NaCl}$ ) to generate the probes. The purified TCP16 and TCP23 proteins were obtained from the TRANSPLANTA consortium (Coego et al., 2014). Briefly, full-length TCP16 and TCP23 expression constructs were cloned in the destination vector pER8 and mobilized into pDONR201 using BP clonase reaction. cDNAs were transferred to destination vector pDEST-TH1 using LR clonase, yielding Maltose Binding Proteins (MBP) N-terminal fusions and constructs checked by sequencing. MBP-TCP16 and MBP-TCP23 constructs were transformed into BL-21 strain for expression. Induction of bacterial cultures was routinely at $25^{\circ} \mathrm{C}$ for $6 \mathrm{~h}$ with $1 \mathrm{mM}$ Isopropyl $\beta$-D-1-thiogalactopyranoside. Expression of recombinant proteins was assessed by Western blot with an anti MBP antibody (BioLab) (Franco-Zorrilla et al., 2014). MBP-TCP16 and MBP-TCP23 proteins were bound to an amylose resin and eluted using maltose. EMSA was carried out with 960-1320 ng of purified protein, 0.01 pmol labeled probe and $225 \mathrm{x}$ unlabeled probe, as indicated, in binding buffer in 10 $\mu \mathrm{l}$ of total reaction volume. Protein buffer (2x TEN, 1 mM DTT, $1 \mathrm{mM}$ protease inhibitor). Binding buffer (20 mM HEPES-KOH pH 7.8, $100 \mathrm{mM} \mathrm{KCl}, 1 \mathrm{mM}$ EDTA, 0.1\% BSA, 10 ng salmon sperm DNA, $10 \%$ glycerol). Binding reaction was performed at room temperature for $30 \mathrm{~min}$. Electrophoresis was performed at $32 \mathrm{~V}$ on ice in a pre-run $5 \%$ native polyacrylamide gel in TBE buffer. Transfer was performed onto a nylon membrane at $40 \mathrm{~V}$ for $2 \mathrm{~h}$ on ice. Membrane crosslinking was at 120 
$\mathrm{mJ} / \mathrm{cm}^{2} 45-60 \mathrm{~s}$ at $254 \mathrm{~nm}$ in Stratalinker. Streptavidin-HRP conjugate antibody (Pr.Nr.21126, Pierce) was used for detection of the labeled probe. Relative bound DNA was quantified using Image J $1.42 \mathrm{q}$ software ${ }^{1}$. The experiment was repeated at least two independent times.

\section{Biochemical Fractionation}

Plants overexpressing the COPT3-HA fusion protein (AndrésColás et al., 2010) were grown on soil. Chloroplasts were isolated and fractionated into stroma and thylakoids from leaves of 3- to 4-week-old plants as described (Pilon-Smits et al., 2002). Samples were normalized based on the number of chloroplasts and chlorophyll content, as determined by the method of Bruinsma (1961) as described (Pilon-Smits et al., 2002). Proteins were quantified by Bradford (1976) assay and separated by native $15 \%$ PAGE and then blotted on a nitrocellulose membrane. Immunodetection of SEC12, CpNifS, and PC was used as control of ER, stroma and thylakoids proteins with specific antiserum (Bar-Peled and Raikhel, 1997; Pilon-Smits et al., 2002; AbdelGhany et al., 2005). COPT3-HA was detected with anti-HA 3F10 specific antibody (Roche).

For sucrose density gradient fractionation the leaves of 4-week-old plants were ground with mortar and pestle in membrane isolation buffer [20 mM HEPES-KOH, pH 7; $50 \mathrm{mM}$ $\mathrm{C}_{2} \mathrm{H}_{3} \mathrm{KO}_{2} ; 5 \mathrm{mM}$ EDTA; $250 \mathrm{mM}$ sorbitol, $1 \mathrm{mM}$ DTT plus Complete $^{\mathrm{TM}}$ protease inhibitor cocktail (Roche)] and centrifuged at $2,000 \times g$ for $10 \mathrm{~min}$ at $4^{\circ} \mathrm{C} .3 \mathrm{ml}$ of the supernatant were applied to the top of continuous $10 \mathrm{ml} \mathrm{20-60 \%} \mathrm{(w/v)} \mathrm{sucrose}$ gradients, either with or without $5 \mathrm{mM} \mathrm{MgCl} 2$ added and centrifuged at $150,000 \times g$ for $3 \mathrm{~h}$ at $4^{\circ} \mathrm{C}$. Fractions of $0.5 \mathrm{ml}$ were taken from the top and concentrated with TCA. The proteins in the fractions were electrophoresed in 12.5\% SDS-PAGE, blotted and immunodetected using antibodies against the HA epitope (3F10, Roche), the ER SEC12, the plasma membrane $\alpha$-AHA and the mitochondrial PMO35 markers, as described above.

\section{Subcellular Localization in Arabidopsis Protoplasts}

The complete COPT3 coding sequence was obtained from Arabidopsis genomic DNA by PCR using the following specific primers, which introduce the adequate restriction sites for cloning: C3-SalI F, 5' CCACGCGTCG ACATGAACGGCATGAGTGGATC; C3-NcoI R, 5' CCATG CCATGGAACAATGTGATTGAACCTCGG. The C-terminus was fused with the GFP reporter and its expression was controlled by the constitutive CaMV35S promoter through its insertion into the transient expression vector pGFPau with the SpeI and SalI restriction enzymes.

The COPT3-GFP construct was used to transform Arabidopsis protoplasts obtained from the fresh leaf tissue of 3-week-old plants grown on soil, as previously described (Abdel-Ghany et al., 2005). After $16 \mathrm{~h}$ under continuous light at $23^{\circ} \mathrm{C}$ in the wash solution, confocal images were obtained using a fluorescence confocal microscope TCS SP vertical (DM-R) (Leica) equipped

${ }^{1}$ https://imagej.nih.gov/ij/ with an argon ion (458 and $488 \mathrm{~nm}$ ), He-Ne I (543 nm) and $\mathrm{He}-\mathrm{Ne}$ II $(633 \mathrm{~nm})$ excitation laser systems and a $60 \times$ objective lens. The fluorescence signals were detected at 500-530 nm for GFP and at 650-750 $\mathrm{nm}$ for chlorophyll, after exciting at 488 and $633 \mathrm{~nm}$, respectively.

\section{GUS Staining and Pollen Preparations for Scanning Electron Microscopy}

Assays were performed as described (Jefferson et al., 1987). Briefly, the organs were embedded with the substrate solution

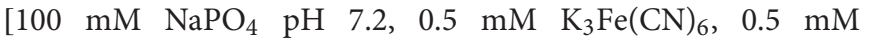
$\mathrm{K}_{4} \mathrm{Fe}(\mathrm{CN})_{6}, 0.1 \%$ (v/v) Triton X-100, $0.5 \mathrm{mM}$ 5-bromo-4-chloro3 -indolyl- $\beta$-D-glucuronide (X-Gluc, AppliChem) and $10 \mathrm{mM}$ EDTA pH 7.2]. Reactions took place at $37^{\circ} \mathrm{C}$.

Pollen was mounted on standard stubs and coated with gold-palladium in a Bio-Rad E5600 ion sputter for $3 \mathrm{~min}$ prior to observation on a Hitachi S4100 FE scanning electron microscope. Digital images were acquired with the application EMIP.

\section{Cu Content Measurements}

$\mathrm{Cu}$ content was determined by atomic absorption as described (Andrés-Colás et al., 2006; Carrió-Seguí et al., 2015) at the "Servei Central de Suport a la Investigació Experimental SCSIE" (Universitat de València) and the "Servicios Centrales de Investigación” (Universidad de Almería).

\section{Gene Expression by RT-PCR}

Total RNA was isolated from $A$. thaliana seedlings with trizol reagent (Ambion). RNA was quantified by UV spectrophotometry and its integrity was visually assessed on ethidium bromide-stained agarose gels. Total RNA $(1.5 \mu \mathrm{g})$ was first converted into cDNA by reverse transcription (RT) using SuperScript II reverse transcriptase (Invitrogen) and anchored oligo $(\mathrm{dT})_{15}$ (Roche) and $18 \mathrm{~S}$ reverse primer. PCR was performed under the following conditions to maintain a linear response in the range of the cDNA concentrations used (see Supplementary Table SIV for the primer-specific sequences): 30 cycles, except 20 cycles for $18 \mathrm{~S}$, of three temperature segments of $30 \mathrm{~s}\left(\mathrm{Td} 94^{\circ} \mathrm{C} / \mathrm{Th} 55^{\circ} \mathrm{C} / \mathrm{Te} 72^{\circ} \mathrm{C}\right)$. The PCR products were visualized in $2 \%$ agarose gels. Real-time PCRs (qPCR) were carried out with SYBR-Green qPCR Super-Mix-UDG with ROX (Invitrogen) and specific oligonucleotides (Supplementary Table SV) in a StepOnePlus Real-Time PCR System (Applied Biosystems) under 1 cycle of $95^{\circ} \mathrm{C}$ for $2 \mathrm{~min}$ and 40 cycles consisting in $95^{\circ} \mathrm{C}$ for $30 \mathrm{~s}$ and $60^{\circ} \mathrm{C}$ for $30 \mathrm{~s}$. The results correspond to the comparative $\mathrm{Ct}$ (cycle threshold) method $(\triangle \Delta \mathrm{Ct})$. The UBQ10 gene was used as a loading control. Values are relative expression with respect to the first sample in each graph, in arbitrary units.

\section{Computer-Assisted Sequence}

The theoretical promoter sequences analysis was performed by Patmatch from TAIR ${ }^{2}$.

${ }^{2}$ www.arabidopsis.org 


\section{RESULTS}

\section{COPT3 Protein Was Intracellular Localized}

The COPT3 gene (At5g59040) is located on chromosome V of the A. thaliana genome, adjacent to COPT1. The two genes are organized head-to-head in opposite orientations separated by 2,266 bp (Supplementary Figure S1A). The COPT3 gene encodes a 151 amino acid protein that displays features, which are conserved in COPT/CTR-type transport proteins. These conserved features include three transmembrane domains (TMDs) with an external amino terminus, containing a conserved Met residue and a cytosolic carboxy terminus, as well as the $\mathrm{Mx}_{3} \mathrm{M}$ and the $\mathrm{Gx}_{3} \mathrm{G}$ motifs within TMD2 and TMD3, respectively (Peñarrubia et al., 2010; Puig, 2014).

The $1.4 \mathrm{~kb}$ promoter region of the COPT3 gene contains a number of potential cis regulatory elements (Supplementary Figure S1B). One of these is a putative plastid expression box at position -388 . Sequence analysis of the coding region suggested that a putative transit sequence for targeting to the chloroplast may be present in COPT3 $\left(\right.$ PSORT $\left.^{3}\right)$ (Supplementary Figure S1C). In order to analyze its subcellular localization, chloroplasts were isolated from an Arabidopsis transgenic line expressing the COPT3 coding sequence tagged with the human influenza hemagglutinin (HA) epitope under the control of the $35 S$ cauliflower mosaic virus (CaMV35S) promoter (COPT3-HA) (Andrés-Colás et al., 2010). The analysis of isolated chloroplast fractions clearly indicated that COPT3 was not present in plastids (Supplementary Figures S2A,C).

Next, COPT3 subcellular localization was analyzed by transient expression in Arabidopsis protoplasts of the COPT3 coding region tagged with the green fluorescence protein (GFP) under the control of the CaMV35S promoter (COPT3-GFP) (Supplementary Table SI). The signal obtained confirmed an intracellular localization of COPT3 excluding the plasma membrane and chloroplasts (Figure 1A). Moreover, sucrose density gradient fractionation of membranes from leaves of plants expressing the COPT3-HA construct indicated that the COPT3 distribution pattern is more similar to the ER protein marker SEC12 than to the other markers, such as the mitochondrial PMO35 protein or the plasma membrane $\alpha$-AHA protein (Supplementary Figures S2B,D). These results point to a putative COPT3 localization in the endomembrane system, maybe in the ER.

\section{COPT3 Was Mainly Expressed in Pollen and Vascular Bundles}

The analysis of the COPT3 promoter (Supplementary Figure S1B) indicated the presence of several GTGA boxes (7), described in the late pollen g10 gene promoter (Rogers et al., 2001). Additionally, one of the two co-dependent elements responsible for the pollen-specific activation of tomato LAT52 gene (Bate and Twell, 1998), the AGAAA element, were present at multiple positions (12). There were also several boxes for expression in

\footnotetext{
${ }^{3}$ https://psort.hgc.jp/
}

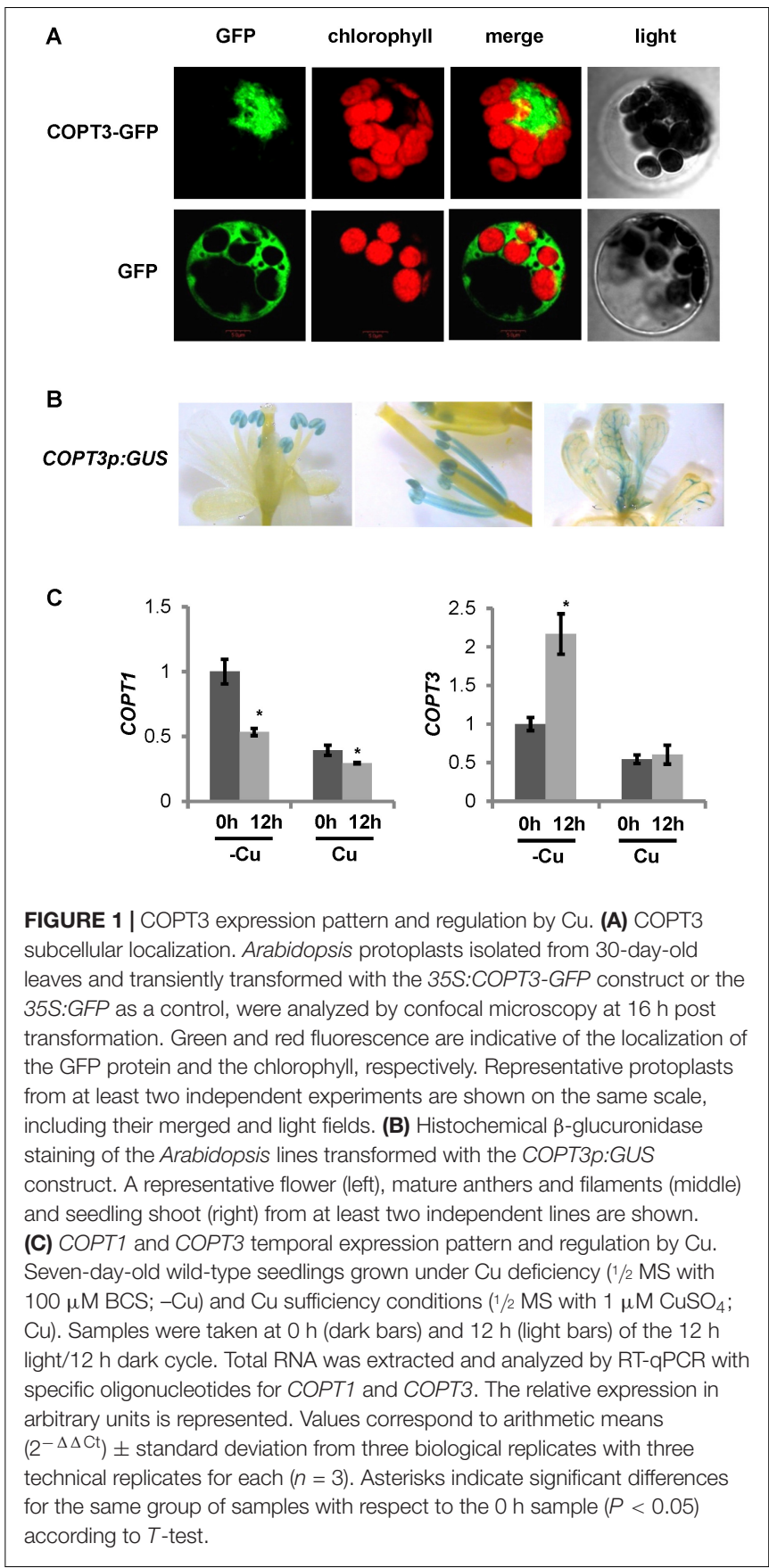

embryo (3), endosperm (4) and aleurone (2) (Supplementary Figure S1B).

In order to determine the tissue expression pattern of COPT3 throughout the plant, we first performed RT-PCR analysis from various organs of adult plants. The result indicated that COPT3 expression was detected in flowers and dried seeds, but also in stems and leaves, whereas it was hardly detectable in roots (Supplementary Figure S3A). These results were consistent with the Genevestigator database ${ }^{4}$, which also indicated that overall

${ }^{4}$ https://genevestigator.com/gv/doc/intro_plant.jsp 
levels of COPT3 expression were low throughout the plant life cycle compared to other COPT family members.

To further study the COPT3 spatial expression pattern, stable transgenic Arabidopsis lines harboring the GUS reporter gene driven by the COPT3 promoter (COPT3p:GUS) were obtained (Supplementary Table SI). During the development of reproductive organs, GUS staining was observed in anthers with a strong signal in pollen (Figure 1B, left). Accordingly, GUS staining was detected in the stamen filaments only when the styles were elongating (Figure 1B, middle). Moreover, GUS staining was also detected in the leaf vascular bundles (Figure 1B, right).

\section{COPT3 Expression Was Up-Regulated at Dusk and Down-Regulated by $\mathrm{Cu}$}

The COPT3 promoter also displayed regulatory elements conserved in light regulated genes, denoted as I-box (GATAA), as well as an element (CAANNNNATC) required for the tomato $L H C$ circadian expression and an Evening Element (AAAATATCT) involved in circadian regulation (Terzaghi and Cashmore, 1995; Harmer et al., 2000; Rawat et al., 2005) (Supplementary Figure S1B). Moreover, based on the DIURNAL DataBase $^{5}$ (Mockler et al., 2007), COPT3 expression oscillated with a phase of around $24 \mathrm{~h}$ under different circadian and diurnal conditions and peaked at $12 \mathrm{~h}$ (end of light period) of the $12 \mathrm{~h}$ light/12 h dark neutral photoperiod cycle (Supplementary Figure S3B). Furthermore, it was previously shown that altered $\mathrm{Cu}$ transport, through COPT1 and COPT3 overexpression, affected circadian rhythms regulation (Andrés-Colás et al., 2010). Taken together, these data may indicate a COPT3 temporal regulation. As a first approach to address its study, COPT3 expression was tested at 0 and $12 \mathrm{~h}$ in 7-day-old seedlings grown on neutral photoperiod conditions. The result confirmed the higher COPT3 expression at $12 \mathrm{~h}$ (end of the light period), opposite to COPT1 expression that was higher at $0 \mathrm{~h}$ (start of the light period), under $\mathrm{Cu}$ deficiency (Figure 1C). This result confirmed our previous data on the temporal expression of other pmCOPT members, such as COPT2 and COPT6, both peaking at dawn (Perea-García et al., 2016a), whereas the other imCOPT, COPT5, peaked at dusk (not shown). These data are also in agreement with data in the DIURNAL DataBase for the pmCOPT and imCOPT expression, where both subfamily member types oppositely oscillated during the diurnal cycle.

Moreover, the COPT3 promoter displayed three putative $\mathrm{Cu}$ deficiency response elements (GTAC) (Supplementary Figure $\mathrm{S} 1 \mathrm{~B})$, previously described in the promoters of $\mathrm{Cu}$-deficiency regulated genes that may be target sites for SPL7 (Yamasaki et al., 2009; Bernal et al., 2012). Although COPT3 expression was previously reported to be independent of the $\mathrm{Cu}$ levels (Sancenón et al., 2003), the presence of these elements suggested a possible up-regulation of COPT3 under $\mathrm{Cu}$ deficiency. In order to check if COPT3 was differentially regulated by $\mathrm{Cu}$ over day and night, samples of seedlings grown under $\mathrm{Cu}$ deficiency and excess were checked by RT-qPCR at 0 and $12 \mathrm{~h}$ (Figure 1C). COPT3 expression was significantly increased under $\mathrm{Cu}$ deficiency, specifically at $12 \mathrm{~h}$ (end of the light period).

${ }^{5}$ http://diurnal.mocklerlab.org/
Furthermore, a wide range of $\mathrm{Cu}$ concentrations were tested and, in general, higher COPT3 expression levels were observed in $\mathrm{Cu}$ deficiency media when compared to $\mathrm{Cu}$ sufficiency or $\mathrm{Cu}$ excess (Supplementary Figure S3C). However, the temporal specific increase of COPT3 expression under $\mathrm{Cu}$ deficiency at $12 \mathrm{~h}$, did not correlate to the expression peak of SPL7 at $0 \mathrm{~h}$ (Perea-García et al., 2016a).

\section{Two Independent TPT TCP16 Lines Were Sensitive to Cu Deficiency}

In order to find regulatory factors involved in the temporal pattern of COPT3 expression, a screen of a conditional overexpression TF library, denoted TRANSPLANTA (TPT) (Coego et al., 2014), was performed under $\mathrm{Cu}$ deficiency conditions. The TRANSPLANTA collection contains 634 Arabidopsis TFs transferred into a vector (pER8) that conferred a $\beta$-estradiol-inducible gene overexpression (Zuo et al., 2000). At least, two independent single insertion and homozygous transgenic lines were generated for each TF (Coego et al., 2014). Reporter lines under the same promoter ( $p E R 8 G$ :GUS-GFP) were used to optimize the expression conditions in our experimental set up (Supplementary Figure S4A). The treatment with 2 $\mu \mathrm{M} \beta$-estradiol induced reporter expression after $12 \mathrm{~h}$ and treatment with $100 \mu \mathrm{M}$ BCS did not modify GUS expression (Supplementary Figure S4B). Based on these results, a screen was performed in 7-day-old seedlings germinated on $1 / 2$ MS medium and then grown on $100 \mu \mathrm{M}$ BCS with $2 \mu \mathrm{M} \beta$-estradiol. Afterward, seedlings were transferred to fresh plates containing $10 \mu \mathrm{M} \mathrm{Cu}$ and $2 \mu \mathrm{M} \beta$-estradiol for checking the recovery of root growth with the aim to discard lines with phenotypes unrelated to $\mathrm{Cu}$ deficiency. The copt5 mutant line, which exhibited a defect in root elongation under $\mathrm{Cu}$ deficiency (Garcia-Molina et al., 2011) and WT seedlings were used as controls (Supplementary Figure S4C).

One of the TF families in the TPT lines with a higher percentage of the members showing a short root phenotype in the screen under $\mathrm{Cu}$ deficiency, which was reverted under high $\mathrm{Cu}$, was the TCP family (not shown). The TRANSPLANTA collection contains TPT lines for 17 TCPs out of a total of 24 members present in the Arabidopsis genome. TPT lines from six of them (TCP14, TCP16, TCP19, TCP20, TCP22, and TCP24) displayed a short root phenotype under $\mathrm{Cu}$ deficiency, which reverted under high $\mathrm{Cu}$ (Table 1). All of them belong to the TCP class I PCF, except TCP24. It is noteworthy that most TCP factors display putative $\mathrm{Cu}$ deficiency responsive GTAC boxes in their proximal promoters (500 bp), except TCP4 and TCP17 (Table 1). Thus, TPT lines positive in the screening corresponded to TCPs that all contain GTAC boxes. Among them, TCP16 (At3g45150) was chosen for further study since the similar curly leaves phenotype found in plants where TCP16 was fused to a repressor domain (Uberti-Manassero et al., 2016) and in plants overexpressing COPT1 and COPT3 (Andrés-Colás et al., 2010; Garcia-Molina et al., 2013).

Two independent TPT TCP16 lines, TPT 3.45150.1B (TPT TCP16-B) and TPT 3.45150.1I (TPT TCP16-I) (Supplementary Table SI), were sensitive to $\mathrm{Cu}$ deficiency, as shown by a reduced root elongation (Figure 2A). The reduced root length 
TABLE 1 | TCPs characteristics and screening results.

\begin{tabular}{|c|c|c|c|c|c|c|c|c|c|}
\hline TCP & MIPS code & Class & Type & Transplanta & Screening & $\begin{array}{c}\text { Class I CAREs } \\
\text { GGNCCCAC } \\
\text { TGGGCC GCCCR } \\
\text { GG(A/T)CCC }\end{array}$ & $\begin{array}{c}\text { Class II CAREs } \\
\text { G(T/C)GGNCCC } \\
\text { GGACCA }\end{array}$ & Other CARE versions & CuRE \\
\hline TCP1 & At1g67260 & $\|$ & CYC/TB1 & + & - & & & ATGGATCCAA & $4^{*}$ \\
\hline TCP2 & At4g18390 & $\|$ & $\mathrm{CIN}$ & + & - & + & & 0 & 1 \\
\hline TCP3 & At1g53230 & $\|$ & $\mathrm{CIN}$ & - & N.D. & & & 0 & 1 \\
\hline TCP4 & At3g15030 & $\|$ & $\mathrm{CIN}$ & - & N.D. & + & & 0 & 0 \\
\hline TCP5 & At5g60970 & $\|$ & $\mathrm{CIN}$ & + & - & & & 0 & 3 \\
\hline TCP6 & At5g41030 & I & PCF & + & - & & & 0 & 3 \\
\hline TCP7 & At5g23280 & I & PCF & - & N.D. & + & + & GTGAGCTCCA & 2 \\
\hline TCP8 & At1g58100 & I & PCF & + & N.D. & & & 0 & 1 \\
\hline TCP9 & At2g45680 & I & PCF & + & - & + & & ATGGTCCCAT & $5^{*}$ \\
\hline TCP10 & At2g31070 & $\|$ & CIN & - & N.D. & & & GTGGGCAACA & 1 \\
\hline TCP11 & At2g37000 & I & PCF & + & - & + & & 0 & 5 \\
\hline TCP12 & At1g68800 & $\|$ & CYC/TB1 & - & N.D. & & & 0 & 4 \\
\hline TCP13 & At3g02150 & $\|$ & $\mathrm{CIN}$ & - & N.D. & & & 0 & $3^{*}$ \\
\hline TCP14 & At3g47620 & I & PCF & + & + & & & 0 & 1 \\
\hline TCP15 & At1g69690 & 1 & PCF & + & - & + & & 0 & 4 \\
\hline TCP16 & At3g45150 & 1 & PCF & + & + & & & $\begin{array}{l}\text { GTGGACCTAT } \\
\text { TCAGGTCCAC }\end{array}$ & 2 \\
\hline TCP17 & At5g08070 & $\|$ & CIN & + & - & & & 0 & 0 \\
\hline TCP18 & At3g18550 & $\|$ & CYC/TB1 & + & - & & & 0 & 3 \\
\hline TCP19 & At5g51910 & I & PCF & + & + & + & & GTGGTCGAGG & 2 \\
\hline TCP20 & At3g27010 & I & PCF & + & + & & & 0 & 1 \\
\hline TCP21 & At5g08330 & I & PCF & - & N.D. & + & + & GTGGTCCAAC & 2 \\
\hline TCP22 & At1g72010 & I & PCF & + & + & & & 0 & 3 \\
\hline TCP23 & At1g35560 & I & PCF & + & - & & & $\begin{array}{l}\text { GTTAGACCAA } \\
\text { TTCGGCGCAT } \\
\text { GTGGAAACAG } \\
\text { GTGGGACTAC }\end{array}$ & 2 \\
\hline TCP24 & At1g30210 & $\|$ & $\mathrm{CIN}$ & + & + & & & 0 & 3 \\
\hline
\end{tabular}

TRANSPLANTA, available TPT lines (+) or not (-). Screening, germinated in $1 / 2$ MS medium, grown in $100 \mu M$ BCS and recovered with $10 \mu M$ Cu after $100 \mu M$ BCS. Class I/II CARES, presence (+) of class I/II TCP CAREs as indicated. Other CARE versions, presence of different versions of the TCP motifs as indicated. CuRE, number of GTAC motifs in the first 500 bp upstream (*, 3 GTAC motifs along 65 bp). Motifs were considered in the first 500 bp upstream and in both strains.

was specifically linked to the $\mathrm{Cu}$ deficiency since the root length defect was not observed in the presence of excess $\mathrm{Cu}$ (Figure 2). Moreover, this phenotype was indeed due to the induced overexpression of TCP16 since it was not observed in the TPT TCP16 lines in the absence of $\beta$-estradiol (Supplementary Figure S4C).

\section{The TCP16 Transcription Factor Bound the COPT3 Promoter}

The promoters of genes participating in $\mathrm{Cu}$ homeostasis were analyzed for the presence of putative cis CARE elements recognized by TCPs. This indicated that COPT3 and COPT5 were the only members of the COPT family that displayed putative CAREs (Supplementary Table SII). These CARE elements in the COPT3 (TTGAGCCCAT) and COPT5 (GTGAGCCCAC) promoters where identified as a specific version of the previously described TCP16 CARE (Martín-Trillo and Cubas, 2010).

In order to check if TCP16 had a direct effect on imCOPTs regulation, binding to the promoter regions containing the putative CARE elements in COPT3 and COPT5 promoters (Supplementary Table SIII) was analyzed by Electrophoretic Mobility Shift Assay (EMSA) with the purified TCP16 protein (provided by the TRANSPLANTA consortium) (Coego et al., 2014). TCP16 interacted with the COPT3 promoter, as shown by a retarded COPT3 probe band in the presence of the TCP16 protein (Figure 3). An excess of COPT3 unlabeled probe reduced the TCP16 binding, as shown by a lower intensity of the retarded COPT3 probe band in the presence of the TCP16 protein. However, with the same amount of the COPT2 unlabeled probe (the COPT2 promoter has no CARE; Supplementary Table SIII), a minor reduction was observed, pointing to the specificity of the TCP16 interaction with the COPT3 promoter. As well as COPT3, TCP16 also bound the COPT5 promoter and specifically compete with an excess of the COPT5 but not of the COPT2 unlabeled probe (Figure 3). TCP23 is a class I TCP member involved in plant development (Balsemão-Pires et al., 2013) that resulted negative in the TPT screening (Table 1). Under the same experimental conditions, no interactions of TCP23 with the COPT3 (Supplementary Figure S5A) and the COPT5 


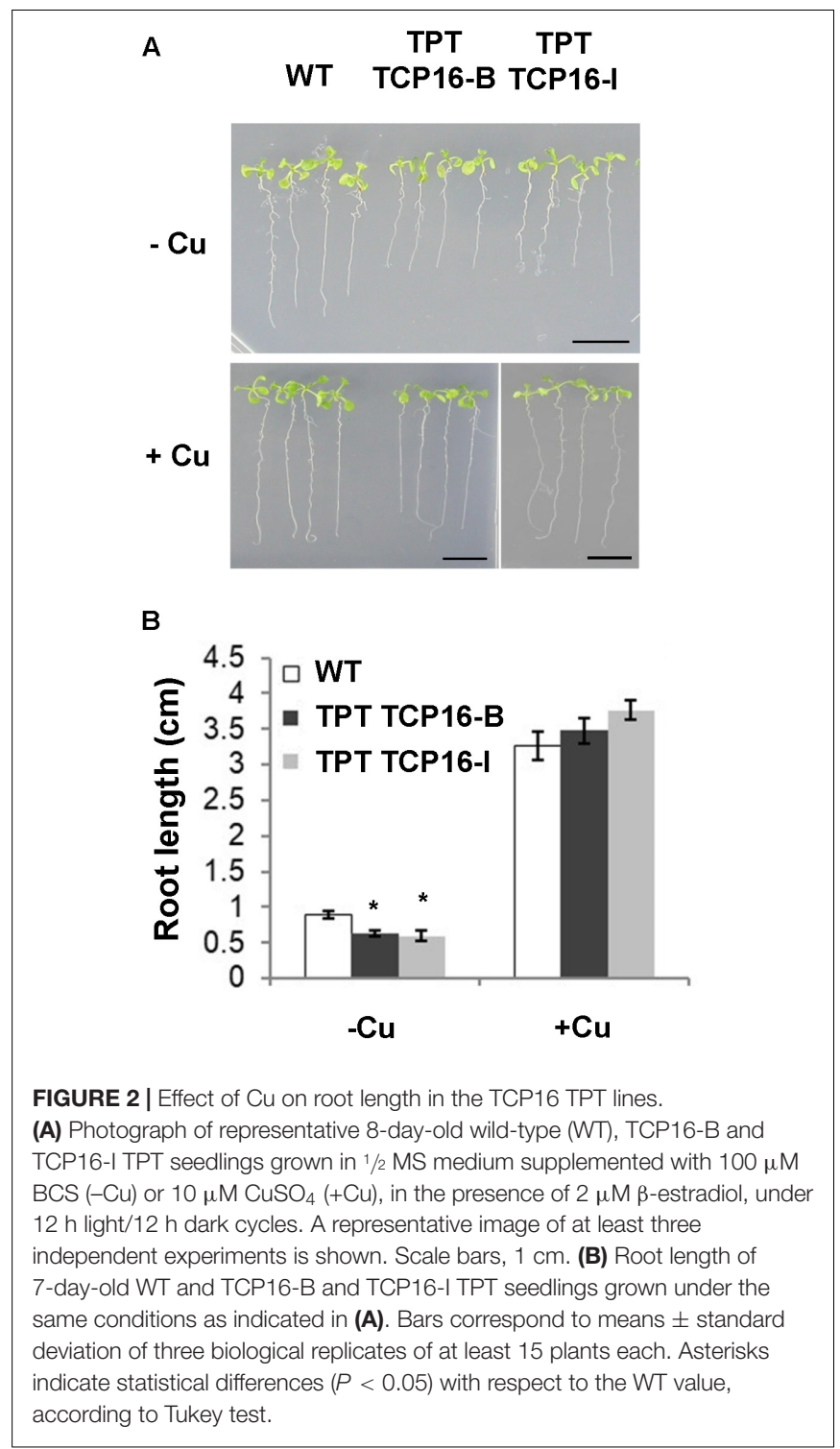

promoters (Supplementary Figure S5B) were detected. Taken together, the TCP16 TF specifically bound to the COPT3 and COPT5 promoters in vitro.

\section{TCP16 Was Involved in Repression of COPT3 Expression}

To check the effect of TCP16 on COPT3 expression, TCP16 and COPT3 mRNA levels were determined in 7-day-old TPT TCP16 seedlings at different times after $\beta$-estradiol induction. Shortterm kinetics indicated that TCP16 expression levels increased 4-5 times after $24 \mathrm{~h}$ induction in both lines (Figure 4A). In parallel to the increase in TCP16 expression at $24 \mathrm{~h}$ after induction, COPT3 expression levels were reduced to $25-15 \%$ (Figure 4B). Besides, long-term TCP16 overexpression by $\beta$-estradiol was dependent on the diurnal time, being higher at $12 \mathrm{~h}$ of the neutral photoperiod cycle (Figure 4C) and provoked a repression of COPT3 expression, specifically at this time of the

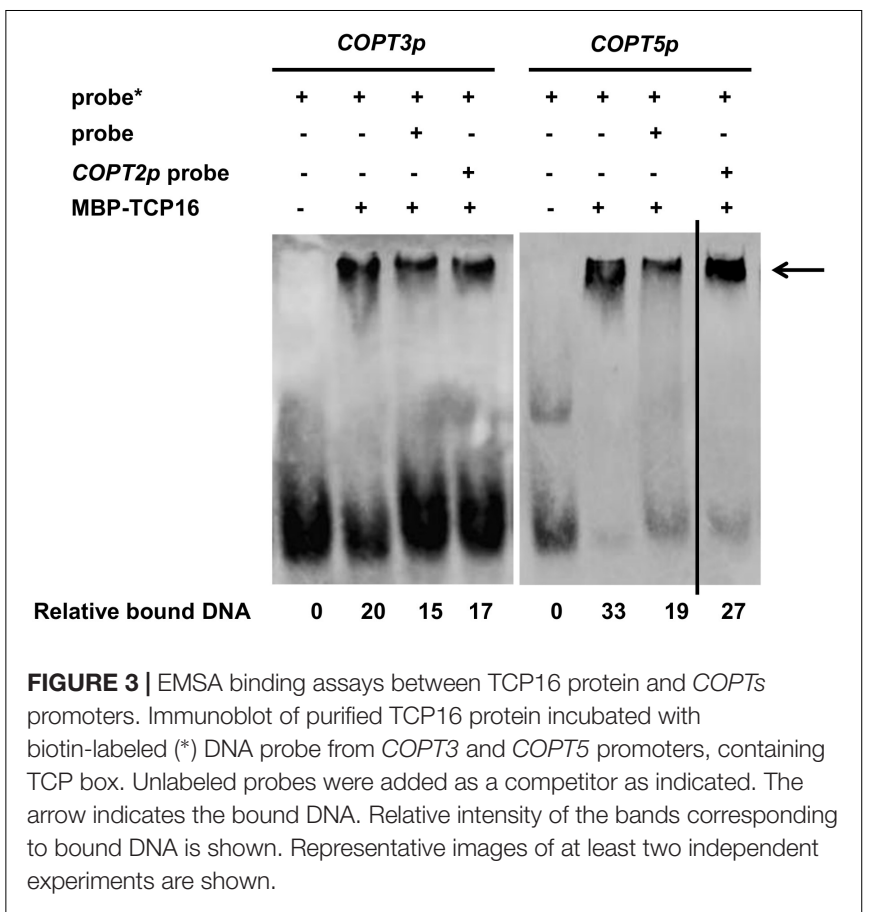

day, under $\mathrm{Cu}$ deficiency (Figure 4D). As a control, the GFP-GUS line showed similar levels of GUS overexpression at 0 and $12 \mathrm{~h}$ of the neutral photoperiod cycle (Supplementary Figure S4A) and other TPT lines showed a robust $\beta$-estradiol-dependent induction of the TF transgene although to a different extent depending on the line (Coego et al., 2014). These data pointed to a repressive TCP16 role on COPT3 expression.

\section{TCP16 Expression Was Up-Regulated at Dawn and by $\mathrm{Cu}$}

Since the TCP16 promoter contains a putative SPL7-responsive GTAC box (Table 1), we checked its expression in WT seedlings in the same samples that were used for COPT3 expression analysis (Figure 1C). The results indicated that TCP16 expression was higher at $0 \mathrm{~h}$ than at $12 \mathrm{~h}$ of the $12 \mathrm{~h}$ light/12 h dark cycle, under $\mathrm{Cu}$ deficiency (Figure 5A). These results may point to a diurnal oscillation of TCP16 expression opposite to the one shown by COPT3. Unfortunately, the TCP16 expression pattern is unavailable in the DIURNAL DataBase to be compared with the results shown here. Moreover, TCP16 expression was significantly higher under $\mathrm{Cu}$ excess at $12 \mathrm{~h}$ with respect to $\mathrm{Cu}$ deficiency, thus high transcript levels remained along day and night under $\mathrm{Cu}$ excess (Figure 5A), coinciding with the reduction in COPT3 expression (Figure 1C). Taken together, these data pointed to a role for TCP16 as a temporal transcriptional repressor of COPT3, specially at dawn under $\mathrm{Cu}$ deficiency and along day and night under $\mathrm{Cu}$ excess.

$\mathrm{Cu}$ levels were determined in the conditionally overexpressing TPT TCP16-B and TPT TCP16-I lines (Figure 5B). TPT TCP16 lines had lower $\mathrm{Cu}$ content than WT under $\mathrm{Cu}$ deficiency. This result pointed to affected $\mathrm{Cu}$ uptake. To test this possibility, the expression of pmCOPTs (COPT1 and COPT2) was analyzed. Both 

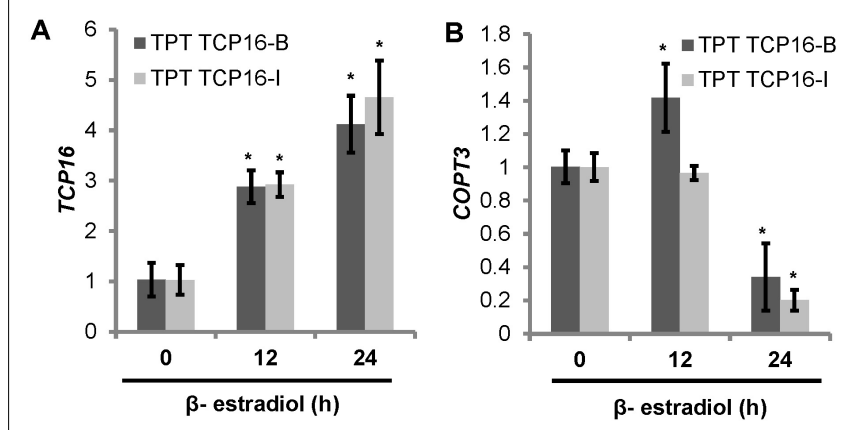

C

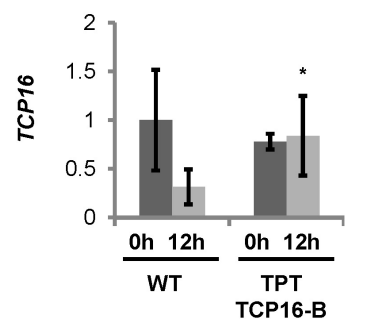

D

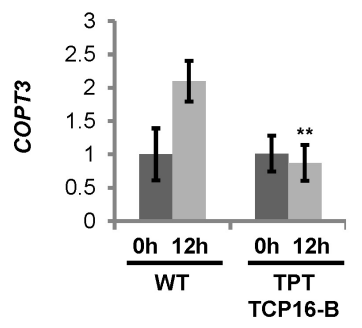

FIGURE 4 | Expression of TCP16 and COPT3 under different conditions in the TCP16 TPT lines. (A,B) Kinetics of TCP16 and COPT3 expression in TCP16 TPT lines by $\beta$-estradiol. Seven-day-old TCP16-B (dark bars) and TCP16-I (light bars) TPT seedlings grown in $1 / 2$ MS medium supplemented with 100 $\mu \mathrm{M}$ BCS. Samples were taken at indicated times, after treatment with $2 \mu \mathrm{M}$ $\beta$-estradiol at $\mathrm{O}$ h of the $12 \mathrm{~h}$ light/12 $\mathrm{h}$ dark cycle in day 7 . Total RNA was extracted and analyzed by RT-qPCR with specific oligonucleotides for TCP16 (A) and COPT3 (B). The relative expression in arbitrary units is represented. Values correspond to arithmetic means $\left(2^{-\Delta \Delta C t}\right) \pm$ standard deviation from three biological replicates with three technical replicates for each $(n=3)$. Asterisks indicate significant differences $(P \leq 0.05)$ according to $T$-test. (C,D) TCP16 and COPT3 temporal expression. Six-day-old wild-type (WT) and TPT TCP16-B seedlings grown in 1/2 MS medium supplemented with $100 \mu \mathrm{M}$ BCS and $2 \mu \mathrm{M} \beta$-estradiol. Samples were taken at $\mathrm{O}$ h (dark bars) and $12 \mathrm{~h}$ (light bars) of the $12 \mathrm{~h}$ light/12 $\mathrm{h}$ dark cycle. Total RNA was extracted and analyzed by RT-qPCR with specific oligonucleotides for TCP16 (C) and COPT3 (D). The relative expression in arbitrary units is represented. Values correspond to arithmetic means $\left(2^{-\Delta \Delta \mathrm{Ct}}\right) \pm$ standard deviation from at least three biological replicates $(n \geq 3)$. Asterisks indicate significant differences for the same group of samples respect to the WT line $\left({ }^{*} P \leq 0.1 ;{ }^{* *} P \leq 0.04\right)$ according to $T$-test.

pmCOPT were selectively reduced at $12 \mathrm{~h}$ in TPT TCP16-B under $\mathrm{Cu}$ deficiency conditions (Figures 5C,D), despite the absence of TCP16 binding boxes in their promoters (Supplementary Table SII).

\section{The Loss-of-Function of TCP16 Exhibited Copper-Related Phenotypes}

In order to have a better understanding of the role of TCP16 in regulating $\mathrm{Cu}$ homeostasis, we used both a RNA interference line TCP16RNAi (Takeda et al., 2006) and a T-DNA insertion mutant tcp16 (N462818) (Supplementary Table SI). The tcp16 mutant contains the T-DNA insert at $+110 \mathrm{bp}$ of the TCP16 coding sequence (Supplementary Figures S6A,B). A homozygous tcp16 line was selected (Supplementary Figure S6C) and the loss of the TCP16 expression at $0 \mathrm{~h}$ corroborated by RT-qPCR (Supplementary Figure S6D). The growth of tcp16 was checked under $\mathrm{Cu}$ deficiency and excess in the medium.

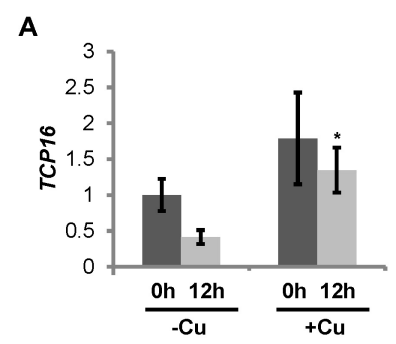

B

C

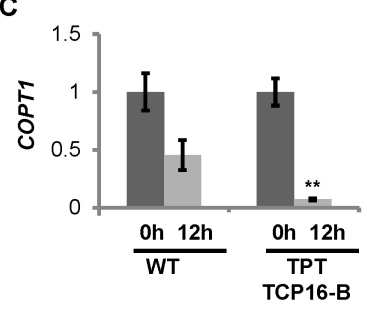

D

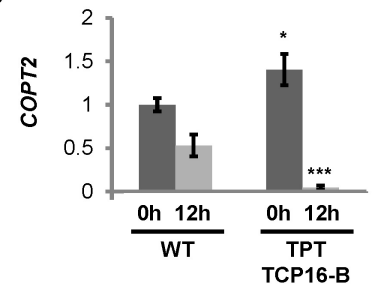

FIGURE 5 | TCP16 temporal expression pattern, regulation by $\mathrm{Cu}$, and $\mathrm{Cu}$ status in the TCP16 TPT lines. (A) TCP16 expression. Six-day-old wild-type seedlings grown in $1 / 2 \mathrm{MS}$ medium (MS) and the same medium supplemented with $100 \mu \mathrm{M}$ BCS $(-\mathrm{Cu})$ or $10 \mu \mathrm{M} \mathrm{CuSO}_{4}(+\mathrm{Cu})$. Samples were taken at $\mathrm{O} \mathrm{h}$ (dark bars) and $12 \mathrm{~h}$ (light bars) of the $12 \mathrm{~h}$ light/12 $\mathrm{h}$ dark cycle. Total RNA was extracted and analyzed by RT-qPCR with specific oligonucleotides for TCP16. The relative expression in arbitrary units is represented. Values correspond to arithmetic means $\left(2^{-\Delta \Delta \mathrm{Ct}}\right) \pm$ standard deviation from at least three biological replicates $(n \geq 3)$. Asterisk indicates significant differences for the same group of samples with respect to the other conditions $(P \leq 0.002)$ according to $T$-test. (B) Cu content in TPT TCP16 plants. Seven-day-old wild-type (white bars), TCP16-B (dark gray bars) and TCP16-I (light gray bars) TPT seedlings grown in $1 / 2$ MS medium supplemented with $100 \mu \mathrm{M}$ BCS $(-\mathrm{Cu})$ or with $10 \mu \mathrm{M} \mathrm{CuSO}_{4}(+\mathrm{Cu})$, in the presence of $2 \mu \mathrm{M} \beta$-estradiol, under $12 \mathrm{~h}$ light/12 h dark cycles. Values correspond to arithmetic

means \pm standard deviation from three biological replicates of $120 \mathrm{mg}$ of DW. Asterisks indicate significant differences between WT and mutant lines in the same condition $(P \leq 0.05)$ according to $T$-test. (C,D) Cu-status marker expression in TPT TCP16 line. Six-day-old wild-type (WT) and TPT TCP16-B seedlings grown in $1 / 2$ MS medium supplemented with $100 \mu \mathrm{M}$ BCS and 2 $\mu \mathrm{M} \beta$-estradiol. Samples were taken at $\mathrm{O}$ h (dark bars) and $12 \mathrm{~h}$ (light bars) of the $12 \mathrm{~h}$ light/12 $\mathrm{h}$ dark cycle. Total RNA was extracted and analyzed by RT-qPCR with specific oligonucleotides for COPT1 (C) and COPT2 (D). The relative expression in arbitrary units is represented. Values correspond to arithmetic means $\left(2^{-\Delta \Delta \mathrm{Ct}}\right) \pm$ standard deviation from four biological replicates $(n=4)$. Asterisks indicate significant differences for the same group of samples with respect to the WT line $\left({ }^{*} P \leq 0.02 ;{ }^{* *} P \leq 0.005 ;{ }^{* *} P \leq 0.0005\right)$ according to $T$-test.

The tcp16 seedlings showed defects in root elongation and fresh weight mostly under $\mathrm{Cu}$ excess (Figures 6A,B), coincident with the conditions where TCP16 was mainly expressed (Figure 5A). Moreover, $\mathrm{Cu}$ content was also determined by atomic absorbance and, whereas conditionally overexpressing TPT TCP16 lines had lower $\mathrm{Cu}$ content than WT under $\mathrm{Cu}$ deficiency (Figure 5B), a decreased level of $\mathrm{Cu}$ content was observed in the loss-of-function TCP16RNAi and tcp16 lines under $\mathrm{Cu}$ excess (Figure 6C).

To check the effect of the TCP16 loss-of-function on COPT3 expression, COPT3 mRNA levels were determined in 7-day-old seedlings of the TCP16RNA $i$ and tcp 16 lines under $\mathrm{Cu}$ excess. An increase in COPT3 expression levels was observed specifically at 

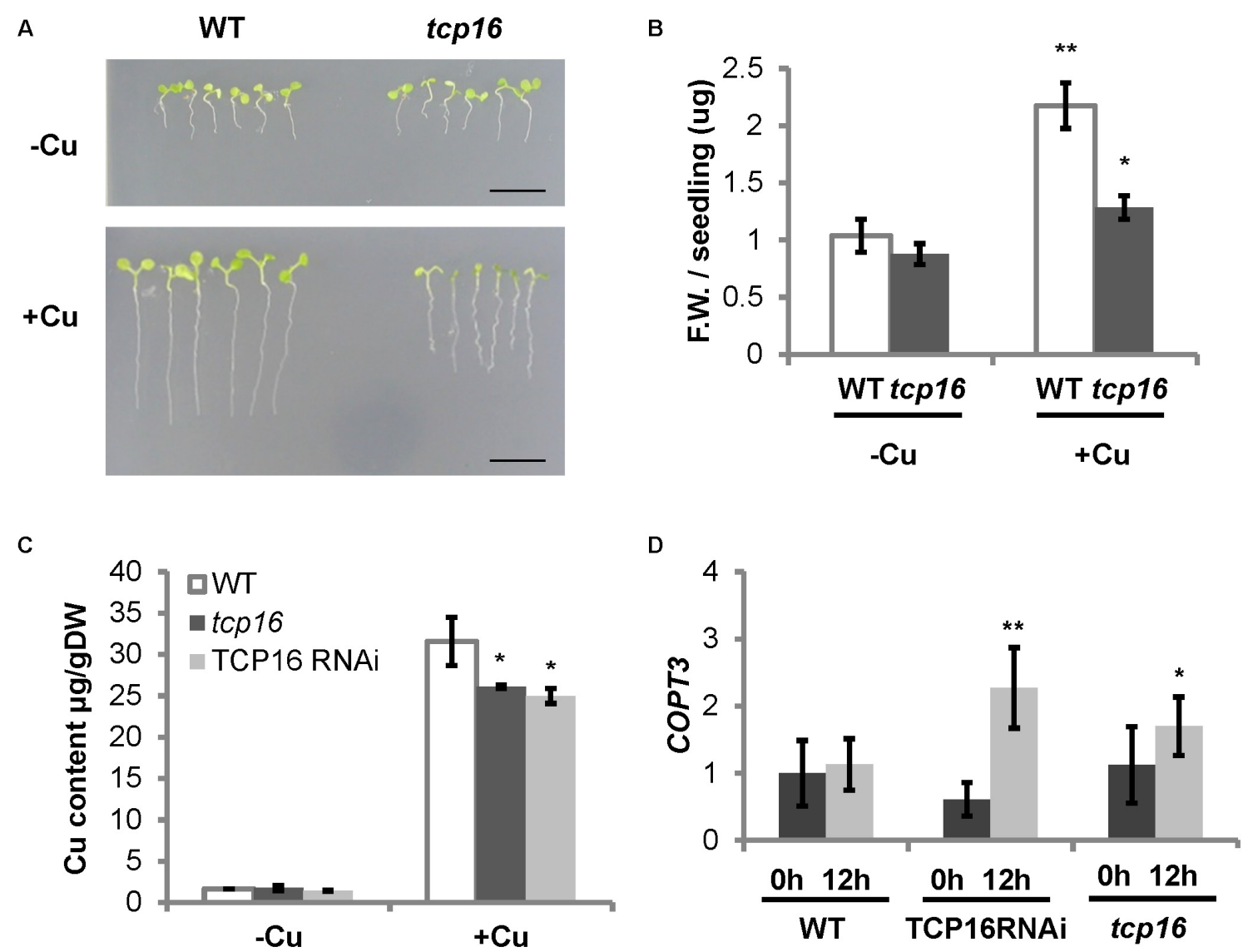

FIGURE 6 | Phenotype of tcp16 seedlings under different Cu status and COPT3 expression in TCP16 RNAi and knockout lines. (A) Photographs of representative 6-day-old wild-type (WT) and tcp 16 seedlings grown in $1 / 2 \mathrm{MS}$ medium supplemented with $100 \mu \mathrm{M} \mathrm{BCS}(-\mathrm{Cu})$ or $10 \mu \mathrm{M} \mathrm{CuSO}$ (+Cu) under $12 \mathrm{~h}$ light/12 h dark cycles. A representative image of at least three independent experiments is shown. Scale bars, $1 \mathrm{~cm}$. (B) Fresh weight of wild-type (white bars) and tcp16 (dark gray bars) 7-day-old seedlings grown in the same conditions shown in (A). Bars correspond to means \pm standard deviation of six biological replicates of five seedlings each. Asterisks indicate significant differences ${ }^{*} P<0.05$; ${ }^{* *} P<0.01$ ) according to Duncan test. (C) Cu content in WT (white bars), TCP16 RNAi (dark gray bars) and tcp16 (light gray bars) 7-day-old seedlings grown in the same conditions shown in (A). Bars correspond to means \pm standard deviation of three biological replicates of $120 \mathrm{mg}$ of DW. Asterisks indicate statistical differences between WT and mutant lines in the same condition $(P<0.05)$ according to $T$-test. (D) COPT3 expression. Six-day-old wild-type (WT), TCP16 RNAi and tcp 16 seedlings grown in $1 / 2 \mathrm{MS}$ medium supplemented with $10 \mu \mathrm{M} \mathrm{CuSO} \mathrm{C}_{4}$. Samples were taken at $0 \mathrm{~h}$ (dark bars) and $12 \mathrm{~h}$ (light bars) of the $12 \mathrm{~h}$ light/12 $\mathrm{h}$ dark cycle. Total RNA was extracted and analyzed by RT-qPCR with specific oligonucleotides for COPT3. The relative expression in arbitrary units is represented. Values correspond to arithmetic means $\left(2^{-\Delta \Delta \mathrm{Ct}}\right) \pm$ standard deviation from at least three biological replicates $(n \geq 3)$. Asterisks indicate significant differences for the same group of samples with respect to the WT line $\left(* P \leq 0.06 ; *^{*} P \leq 0.009\right)$ according to $T$-test.

the end of the light period (12 h) (Figure 6D). This effect was the opposite to the one observed in the conditionally overexpressing TPT TCP16-B line (Figure 4D), further pointing to the function of TCP16 as a repressor of COPT3.

\section{COPT3 Function Was Required for Proper Repression of TCP16}

The possibility that COPT3 function could reciprocally affect TCP16 expression was also checked. For that purpose, we analyzed the TCP16 expression in transgenic lines with altered COPT3 expression levels and used the COPT3-HA line (Andrés-Colás et al., 2010) and loss-of-function copt3 mutant (GK633G06) (Supplementary Table SI). The copt3 mutant contains a T-DNA insertion at +109 bp of the COPT3 coding sequence (Supplementary Figure S7A). A homozygous copt3 line was selected (Supplementary Figure S7B) and the loss of the COPT3 expression in flowers corroborated by RT-qPCR (Supplementary Figure S7C). The COPT3-HA line was sensitive to $\mathrm{Cu}$ excess, as shown by a reduction in root elongation and alteration of the flower morphology and flowering time (Andrés-Colás et al., 2010). On the contrary, the copt3 mutant was more sensitive to $\mathrm{Cu}$ deficiency than WT and accordingly accumulated less $\mathrm{Cu}$ than controls (not shown). The levels of the $\mathrm{Cu}$ deficiency marker COPT2 were higher at $12 \mathrm{~h}$ in the copt 3 mutant (Figure 7A), whereas SDH1-2, a mitochondrial marker of Cu excess (Andrés-Colás et al., 2013), was significantly reduced at this time in flowers (Figure 7B) further pointing to decreased $\mathrm{Cu}$ levels in the copt 3 mutant.

The expression analysis showed that TCP16 levels were higher at $12 \mathrm{~h}$ in the copt 3 mutant line, in contrast with a lower expression at $0 \mathrm{~h}$ in the COPT3-HA transgenic line (Figure 7C). 


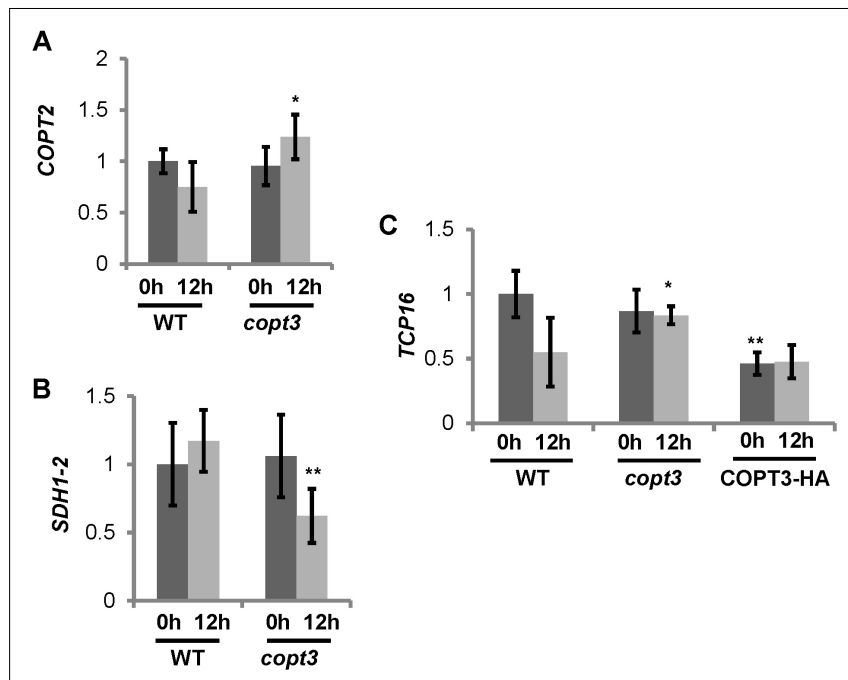

FIGURE 7 | Phenotype of copt3 knockout seedlings under different $\mathrm{Cu}$ status. (A,B) Cu-status marker expression in copt3 lines. Flowers from wild type (WT) and copt3 knockout plants grown in soil. Samples were taken at $0 \mathrm{~h}$ (dark bars) and $12 \mathrm{~h}$ (light bars) of the $12 \mathrm{~h}$ light/12 $\mathrm{h}$ dark cycle. Total RNA was extracted and analyzed by RT-qPCR with specific oligonucleotides for COPT2 $(A)$ and SDH1-2 (B). The relative expression in arbitrary units is represented. Values correspond to arithmetic means $\left(2^{-\Delta \Delta C t}\right) \pm$ standard deviation from at least three biological replicates $(n \geq 3)$. Asterisk indicates significant differences for the same group of samples with respect to the WT line $\left({ }^{*} P \leq 0.04 ;{ }^{*} P \leq 0.03\right)$ according to $T$-test. (C) $T C P 16$ expression in copt3 and COPT3 ${ }^{\mathrm{OE}}$ lines. Six-day-old wild-type (WT), copt3 and COPT3OE seedlings grown in $1 / 2$ MS medium supplemented with $100 \mu$ M BCS. Samples were taken at $\mathrm{O} \mathrm{h}$ (dark bars) and $12 \mathrm{~h}$ (light bars) of the $12 \mathrm{~h}$ light/12 $\mathrm{h}$ dark cycle. Total RNA was extracted and analyzed by RT-qPCR with specific oligonucleotides for TCP16. The relative expression in arbitrary units is represented. Values correspond to arithmetic means $\left(2^{-\Delta \Delta C t}\right) \pm$ standard deviation from at least two biological replicates $(n \geq 2)$. Asterisks indicate significant differences for the same group of samples with respect to the WT line $\left({ }^{*} P \leq 0.15 ;{ }^{*} P \leq 0.005\right)$ according to $T$-test.

These data suggested that, in addition to the already mentioned repression of TCP16 over COPT3, a reciprocal repressing effect of the COPT3 function on TCP16 expression was taking also place.

In agreement with the observation that COPT3 expression was higher in pollen, the copt3 mutant showed a significantly higher percentage of pollen ornamentation defects than the WT plants, but only under $\mathrm{Cu}$ deficient conditions (Figure 8). TCP16 was also highly expressed in pollen and abortion of early pollen development has been shown in the TCP16RNAi plants (Takeda et al., 2006). These results reinforced the relevance of $\mathrm{Cu}$ homeostasis for pollen viability and the temporal and reciprocal regulation established between TCP16 and COPT3, necessary to fully accomplish this crucial process in plants.

\section{DISCUSSION}

COPT1 and COPT3 transporters belong to two subfamilies (pmCOPT and imCOPT, respectively) involved in $\mathrm{Cu}^{+}$uptake from different extra- and intra-cellular pools. The COPT1 and COPT3 are two flanking genes organized head-to-head in opposite orientations. In general, bidirectional activity was shown to be an inherent feature of most promoters, being especially relevant in divergent promoters (Seila et al., 2008; Wakano et al., 2012). In Arabidopsis, 5,763 divergent gene pairs were reported (Krom and Ramakrishna, 2008) and among them, 462 are separated by a small distance $(<250 \mathrm{bp})$ sharing a single bidirectional promoter that may regulate the co-expression of the two genes (Dhadi et al., 2009). The intergenic region between transcriptional start sites of COPT1 and COPT3 is 2,266 bp (Supplementary Figure S1A), a similar size to the 2,177 DNA segment between the genes $c a b 1$ and $c a b 2$ which was shown to function as a bidirectional promoter (Mitra et al., 2009). It is thus possible, that COPT1 and COPT3 spatial expression is co-regulated via the shared bidirectional promoter. Indeed, both were mostly present in pollen, seeds and vascular bundles (Figures 1B and Supplementary Figure S3A) (Sancenón et al., 2004; Bock et al., 2006). However, whereas COPT3 was expressed early in pollen development, COPT1 was expressed at later stages (Bock et al., 2006). Indeed, $\mathrm{Cu}$ is highly required for pollen development and its regulated delivery through COPT transporters could be an important step. Both SPL7 and a Cu-DEFICIENCY-INDUCED TRANSCRIPTION FACTOR 1 (CITF1) belonging to the bHLH family (bHLH160) were recently shown to participate in the regulation of $\mathrm{Cu}$ delivery to the anthers and in jasmonic acid synthesis during $\mathrm{Cu}$ deficiency (Yan et al., 2017).

Our data indicated that COPT3 might be located in a compartment of the secretory pathway, which could be the ER, where COPT3 would recover $\mathrm{Cu}^{+}$from the ER lumen. Although further experimental approaches are required to localize COPT3 to a precise organelle, it is interesting to note that the ER was also the proposed location of the $\mathrm{Cu}$ deficiency sensor SPL7 (Garcia-Molina et al., 2014). SPL7 was proposed to sense both cytosolic and the ER lumen $\mathrm{Cu}$ status. Our COPT3 localization data pointed that COPT3 could be interestingly involved in the partitioning of these two differential Cu pools (Figure 9).

The fact that the COPT3 transcriptional expression pattern was initially described as not being affected by $\mathrm{Cu}$ status in the medium (Sancenón et al., 2003), could be attributed to the particular temporal dependence of the $\mathrm{Cu}$-regulation of COPT3 expression. Both COPT1 and COPT3 present several GTAC elements nearby the translational start sites that could be involved in SPL7-mediated $\mathrm{Cu}$ deficiency responses (Yamasaki et al., 2009; Bernal et al., 2012). In regard to this, the expression in phase of both the activator SPL7 and the target COPT1 could drive a robust $\mathrm{Cu}$ deficiency response for $C O P T 1$ expression, whereas the antiphase expression between the SPL7 and the target COPT3 could temporally affect the intensity of the SPL7-mediated regulation, as already modeled (Peñarrubia et al., 2015). This result suggested that, at the temporal level, the promoter region could be alternatively used in each direction for COPT1 and COPT3 transcription, instead of co-expression. However, the SPL7-mediated antiphase regulation of COPT3 expression cannot explain per se the anti-correlated expression observed at the temporal level between COPT1 and COPT3 driven from a putative bidirectional promoter (Figure 1C), but rather 

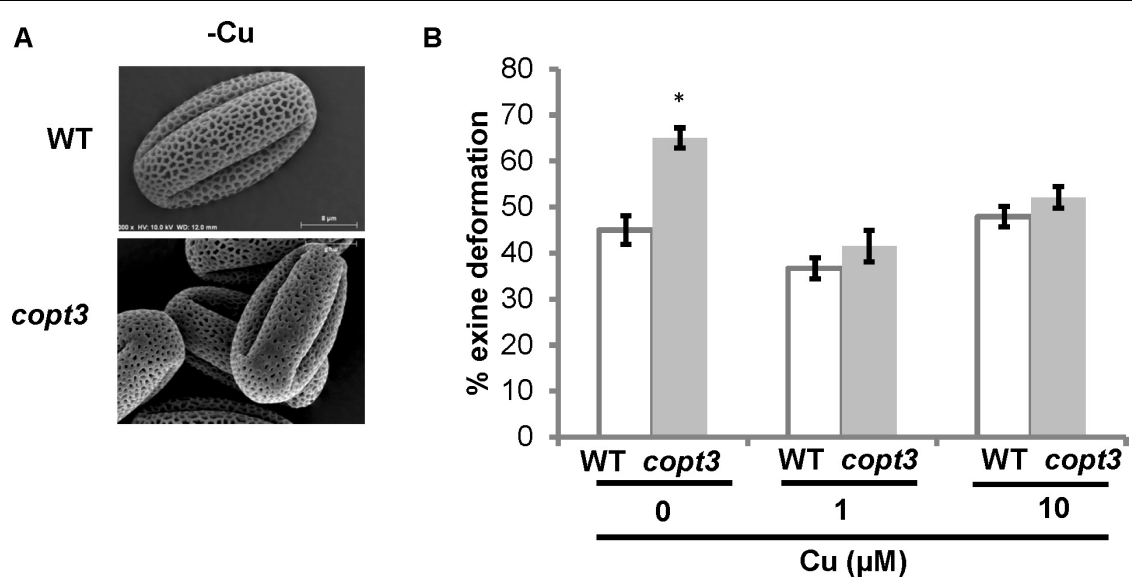

FIGURE 8 | Pollen grains morphology of copt3 knockout plants. (A) Electronic photography of representative wild-type (WT) and copt3 pollen grains obtained from flowers at the anthesis stage. (B) Quantification of exine deformation in pollen grains. The plants were grown in soil under long day conditions and watered with Hoagland' solution with $0(-\mathrm{Cu}), 1$ and $10 \mu \mathrm{M} \mathrm{CuSO}_{4}$. Bars correspond to means \pm standard deviation of five biological replicates of 15 flowers. One hundred pollen grains were analyzed for each genotype and condition. Asterisks indicate statistical differences $(P<0.05)$ according to $Z$-test.

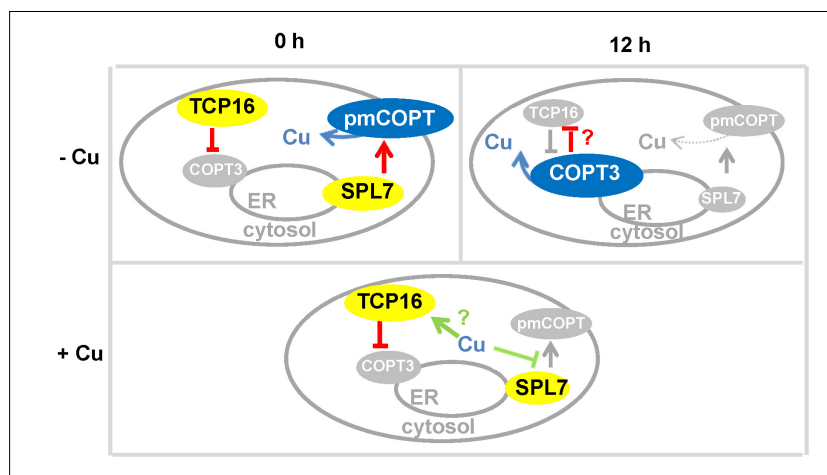

FIGURE 9 | Model for TCP16 function in copper homeostasis. Scheme of the temporal ( 0 and $12 \mathrm{~h}$ ) regulation of pmCOPTs and imCOPT3 expression by TCP16 and SPL7 in wild-type seedlings under different Cu status (-Cu and $+\mathrm{Cu})$.

suggested the presence of other temporal transcriptional regulators.

Thanks to the TRANSPLANTA consortium, we could screen for conditionally inducible TFs that might participate in the response to $\mathrm{Cu}$ availability (Coego et al., 2014). The TCP family was one of the most overrepresented with regard to the number of positive members in the screen. Moreover, the presence of putative elements denoted CAREs in the COPT3 and COPT5 promoters, as well as in other $\mathrm{Cu}$ homeostasis components (Supplementary Table SII), is compatible with a regulatory role of TCPs in Cu homeostasis. We selected the TCP family for further study, because pollen morphology was also affected in plants with altered levels of COPT1, COPT3, and TCP16 (Sancenón et al., 2004; Takeda et al., 2006; this study). Moreover, CHE is a TCP factor that was involved in CCA 1 repression by interacting with TOC1, both components of the circadian clock (PrunedaPaz et al., 2009), which expression was altered in COPT1 overexpressing plants (Andrés-Colás et al., 2010). COPT1 and
COPT3 overexpression displayed similar phenotypes that were attributed to the temporal deregulation of the $\mathrm{Cu}$ entrance that could affect the circadian rhythms (Andrés-Colás et al., 2010). This fact could explain the phenotype observed for the COPT3 overexpressing and copt3 seedlings under $\mathrm{Cu}$ deficiency in this work. Finally, in microarrays analysis performed in transgenic plants with modified levels of COPT2, differential expression of several TCP members was observed (Perea-García et al., 2013).

There are several lines of evidence to support the model that TCP16 represses COPT3 expression. First, TCP16 specifically bound to the COPT3 and COPT5 promoters in vitro as shown by EMSA (Figure 3). And second, COPT3 was repressed as TCP16 expression increased (Figure 4) and conversely, COPT3 was upregulated in a tcp16 mutant (Figure 6). The presence of a putative TCP16 binding site nearby the translational start site of COPT3, but not of COPT1, could account for the particular temporal repression of COPT3. The relative short distance (109 bp) between the GTAC boxes and the putative TCP16 binding site in the COPT3 promoter (Supplementary Figure S1) brings to discussion if there is a competence between SPL7 and TCP16 for binding. Any kind of interaction between the activation and the repression function of SPL7 and TCP16, respectively, is also plausible since TCPs interact with a wide variety of other TF families, including other SPL member in the described TCP4-SPL9 temporal interaction taking place during flower development (Rubio-Somoza et al., 2014; Bemer et al., 2017). Furthermore, as a conclusion of the COPT3 expression analysis, TCP16 could act as a repressor of COPT3-mediated Cu transport in a time specific manner.

Under $\mathrm{Cu}$ deficient conditions, we hypothesized that COPT3-mediated $\mathrm{Cu}$ recovery from the secretory pathway was repressed by TCP16 at $0 \mathrm{~h}$, while the pmCOPT would participate in the uptake extracellular $\mathrm{Cu}$ at this time being activated by SPL7 (Figure 9). Under $\mathrm{Cu}$ excess, pmCOPTs were not activated by SPL7 and TCP16 will further repressed COPT3 and COPT5 along day and night (Figure 9). On the 
other hand, the expression of the pmCOPT transporters at $12 \mathrm{~h}$ could be subjected to a feedback autoregulatory loop that was proposed to act as a biochemical oscillator (Peñarrubia et al., 2010). Moreover, COPT3 and TCP16 were mutually repressing each other's expression. TCP16 may directly act as a COPT3 repressor, whereas COPT3 probably indirectly affected TCP16 expression. Subsequently, $\mathrm{Cu}$ entrance from extracellular pools was prioritized at dawn and $\mathrm{Cu}$ mobilization from internal pools was favored at dusk. Whether this affected cytosolic $\mathrm{Cu}$ or the destiny of $\mathrm{Cu}$ coming from the different pools was being used for separate purposes still deserves further investigation. In addition, HMA5 and RAN1 also display putative CARE elements in their promoters (Supplementary Table SII) that could indicate that $\mathrm{Cu}$ transport in both directions (entrance and exit) through internal membranes was under control of TCPs.

The fine regulation exerted by TCP16 as a repressor of $\mathrm{Cu}$ entrance from internal stores specifically at dawn suggested a temporal division requirement for incompatible processes. Among the possibilities, the avoidance of a putative excessive increase in oxidative stress in this period that could not be properly counteracted. In this sense, $\mathrm{Cu}^{+}$uptake through COPT transporters imposed an increased oxidative stress (RodrigoMoreno et al., 2013) that could interfere at multiple cellular processes and damage biological structures (Ravet and Pilon, 2013). The redox state of the cell was shown to influence the DNA binding ability of class I TCP proteins (Viola et al., 2013). The oxidation of a conserved cysteine residue (C-20) leaded to the formation of intermolecular disulfide bonds that cannot bound target promoters (Viola et al., 2016). Although the C-20 residue is not conserved, a single cysteine (C-107) residue is present in TCP16 (Supplementary Figure S6A).

On the other hand, TCP16 repression could be aimed to protect a $\mathrm{Cu}$ sensitive process operating at dawn. In this sense, a specially $\mathrm{Cu}$ sensitive process that takes place in the mitochondria is the Fe-S cluster assembly, required for multiple processes including the respiratory electron transfer chain (Brancaccio et al., 2017). Since the mitochondrial matrix contains a labile $\mathrm{Cu}^{+}$pool and is also the place where the Fe-S cluster assembly machinery resides, a strict temporal regulated $\mathrm{Cu}$ uptake might prevent a blocking of mitochondrial $\mathrm{Fe}-\mathrm{S}$ protein maturation (Brancaccio et al., 2017). This process is in agreement with the regulatory function of mitochondrial proteins by TCPs (Welchen and Gonzalez, 2006) and is also connecting $\mathrm{Fe}$ and $\mathrm{Cu}$ homeostasis, as already described for the copt2 mutant (Perea-García et al., 2013). Accordingly, tcp16 seedlings were sensitive to $\mathrm{Cu}$ excess (Figure 6), maybe due to an impaired temporal $\mathrm{Cu}$ entrance to the mitochondria. The source of $\mathrm{Cu}$ that reaches organelles from an endosymbiotic origin, such as mitochondria and chloroplasts, remains an unsolved question. Under environmental nutrient deprivation, a putative $\mathrm{Cu}$ source is the lumen of the endocytic compartments that were recently shown to participate in dynamic intracellular metal homeostasis (Blaby-Haas and Merchant, 2014; HongHermesdorf et al., 2014). Although further work is needed to confirm this hypothesis, the internal membrane COPT3 and COPT5 transporters might participate in $\mathrm{Cu}$ delivery from the secretory pathway to organelles under metal deficiency. In agreement, photosynthesis is affected in copt5 mutants (Garcia-Molina et al., 2011). The mitochondrial SDH1-2 promoter displayed 3 putative CARE elements (Welchen and Gonzalez, 2006) and it was shown to be regulated by TCPs (Giraud et al., 2010). Moreover, SDH1-2 was a good marker for mild $\mathrm{Cu}$ excess (Andrés-Colás et al., 2013). In accordance, SDH1-2 expression was down-regulated in the copt3 mutant (Figure 7B). This result suggested that a $\mathrm{Cu}-\mathrm{TCP}$ interplay may mediate mitochondrial SDH1-2 expression. This would constitute a new pathway for gene expression regulation under mild $\mathrm{Cu}$ excess that might be aimed to protect mitochondria from Cu toxicity.

The fact that COPT1 and COPT3 were mostly expressed in vascular tissues points to a role for the temporal differences in metal long distance transport. In this sense, since the higher $\mathrm{Cu}$ affinity for common metal chelators (Álvarez-Fernández et al., 2014), competition with other metals, such as Fe, in the xylem transport could involve a metal interference in long distance transport, especially relevant under metal deficiencies. Although further work will be needed to address this hypothesis, a putative solution could be a metal differential temporal arrangement in vascular transport.

Finally, the in silico analysis of the hormone-responsive cis-elements present in the promoter sequences $(1,000 \mathrm{bp}$ upstream of the five prime untranslated region) from the COPT1 and COPT3 genes indicated a differential hormonal response (Peñarrubia et al., 2015). Major differences were observed for those cis-elements involved in ABA and gibberellic acid (GA) signaling. Whereas the total elements for ABA were 11 and 3 , those for GA were 7 and 20 in the COPT1 and COPT3 promoters, respectively (Peñarrubia et al., 2015). Since the antagonism between ABA and GA is well-known (Weiss and Ori, 2007), as well as their interplay with the circadian clock (Atamian and Harmer, 2016) and their wide crosstalk with TCPs (Nicolas and Cubas, 2016), the results shown here underscore the role of phytohormones in the temporal orchestration of metal homeostasis that might control plant development depending on the environmental nutrient conditions.

\section{AUTHOR CONTRIBUTIONS}

LP conceived the idea and wrote the manuscript. MP, NA-C, and SA-G conceived and performed the COPT3 localization experiments. NA-C performed the TF screening. NA-C and AC-S performed the physiological and molecular experiments in mutant plants.

\section{FUNDING}

This work has been supported by grants BIO2017-87828-C2-1P (LP) and the TRANSPLANTA Consortium (CSD2007-00057) from the Spanish Ministry of Economy and Competitiveness, and by FEDER funds from the European Union. NA-C and AC-S 
were recipients of a predoctoral FPI fellowship from the Spanish Ministry of Economy and Competitiveness.

\section{ACKNOWLEDGMENTS}

We acknowledge the SCSIE (Universitat de València) for the sequencing and greenhouse services, Dr. Sergi Puig for critical reading of the manuscript and Drs. Pablo Vera and José Luis Carrasco (IBMCP-UPV València) for providing the

\section{REFERENCES}

Abdel-Ghany, S. E., Müller-Moulé, P., Niyogi, K. K., Pilon, M., and Shikanai, T. (2005). Two P-type ATPases are required for copper delivery in Arabidopsis thaliana chloroplasts. Plant Cell 17, 1233-1251. doi: 10.1105/tpc.104.030452

Almeida, D. M., Gregorio, G. B., Oliveira, M. M., and Saibo, N. J. (2017). Five novel transcription factors as potential regulators of OsNHX1 gene expression in a salt tolerant rice genotype. Plant Mol. Biol. 93, 61-77. doi: 10.1007/s11103-0160547-7

Álvarez-Fernández, A., Díaz-Benito, P., Abadía, A., López-Millán, A. F., and Abadía, J. (2014). Metal species involved in long distance metal transport in plants. Front. Plant Sci. 5:105. doi: 10.3389/fpls.2014.00105

Andrés-Colás, N., Perea-García, A., Mayo de Andrés, S., Garcia-Molina, A., Dorcey, E., Rodríguez-Navarro, S., et al. (2013). Comparison of global responses to mild deficiency and excess copper levels in Arabidopsis seedlings. Metallomics 5, 1234-1246. doi: 10.1039/c3mt00025g

Andrés-Colás, N., Perea-García, A., Puig, S., and Peñarrubia, L. (2010). Deregulated copper transport affects Arabidopsis development especially in the absence of environmental cycles. Plant Physiol. 153, 170-184. doi: 10.1104/pp. 110.153676

Andrés-Colás, N., Sancenón, V., Rodríguez-Navarro, S., Mayo, S., Thiele, D. J., Ecker, J. R., et al. (2006). The Arabidopsis heavy metal P-type ATPase HMA5 interacts with metallochaperones and functions in copper detoxification of roots. Plant J. 45, 225-236. doi: 10.1111/j.1365-313X.2005.02601.x

Andriankaja, M. E., Danisman, S., Mignolet-Spruyt, L. F., Claeys, H., Kochanke, I., Vermeersch, M., et al. (2014). Transcriptional coordination between leaf cell differentiation and chloroplast development established by TCP20 and the subgroup Ib bHLH transcription factors. Plant Mol. Biol. 85, 233-245. doi: $10.1007 / \mathrm{s} 11103-014-0180-2$

Atamian, H. S., and Harmer, S. L. (2016). Circadian regulation of hormone signaling and plant physiology. Plant Mol. Biol. 91, 691-702. doi: 10.1007/ s11103-016-0477-4

Balsemão-Pires, E., Andrade, L. R., and Sachetto-Martins, G. (2013). Functional study of TCP23 in Arabidopsis thaliana during plant development. Plant Physiol. Biochem. 67, 120-125. doi: 10.1016/j.plaphy.2013.03.009

Bar-Peled, M., and Raikhel, N. V. (1997). Characterization of AtSEC12 and AtSAR1. Proteins likely involved in endoplasmic reticulum and Golgi transport. Plant Physiol. 114, 315-324. doi: 10.1104/pp.114.1.315

Bate, N., and Twell, D. (1998). Functional architecture of a late pollen promoter: pollen-specific transcription is developmentally regulated by multiple stagespecific and co-dependent activator elements. Plant Mol. Biol. 37, 859-869. doi: 10.1023/A:1006095023050

Bemer, M., van Dijk, A. D., Immink, R. G., and Angene, G. C. (2017). Cross-family transcription factor interactions: an additional layer of gene regulation. Trends Plant Sci. 22, 66-80. doi: 10.1016/j.tplants.2016.10.007

Bernal, M., Casero, D., Singh, V., Wilson, G. T., Grande, A., Yang, H., et al. (2012). Transcriptome sequencing identifies SPL7-regulated copper acquisition genes FRO4/FRO5 and the copper dependence of iron homeostasis in Arabidopsis. Plant Cell 24, 738-761. doi: 10.1105/tpc.111.090431

Blaby-Haas, C. E., and Merchant, S. S. (2014). Lysosome-related organelles as mediators of metal homeostasis. J. Biol. Chem. 289, 28129-28136. doi: 10.1074/ jbc.R114.592618

Bock, K. W., Honys, D., Ward, J. M., Padmanaban, S., Nawrocki, E. P., Hirschi, K. D., et al. (2006). Integrating membrane transport with male gametophyte
TCP16 and TCP23 proteins for EMSA analysis. TCP16 RNAi line was kindly provided by Chiharu Ueguchi (Takeda et al., 2006).

\section{SUPPLEMENTARY MATERIAL}

The Supplementary Material for this article can be found online at: https://www.frontiersin.org/articles/10.3389/fpls.2018.00910/ full\#supplementary-material

development and function through transcriptomics. Plant Physiol. 140, 1151-1168. doi: 10.1104/pp.105.074708

Bradford, M. M. (1976). A rapid and sensitive method for the quantitation of microgram quantities of protein utilizing the principle of proteindye binding. Anal. Biochem. 72, 248-254. doi: 10.1016/0003-2697(76) 90527-3

Brancaccio, D., Gallo, A., Piccioli, M., Novellino, E., Ciofi-Baffoni, S., and Banci, L. (2017). [4Fe-4S] Cluster assembly in mitochondria and its impairment by copper. J. Am. Chem. Soc. 139, 719-730. doi: 10.1021/jacs.6b09567

Bruinsma, J. (1961). A comment on the spectrophotometric determination of chlorophyll. Biochim. Biophys. Acta 52, 576-578. doi: 10.1016/0006-3002(61) 90418-8

Carrió-Seguí, A., Garcia-Molina, A., Sanz, A., and Peñarrubia, L. (2015). Defective copper transport in the copt5 mutant affects cadmium tolerance. Plant Cell Physiol. 56, 442-454. doi: 10.1093/pcp/pcu180

Chen, Y.-Y., Wang, Y., Shin, L.-J., Wu, J.-F., Shanmugam, V., Tsednee, M., et al. (2013). Iron is involved in maintenance of circadian period length in Arabidopsis. Plant Physiol. 161, 1409-1420. doi: 10.1104/pp.112.21 2068

Coego, A., Brizuela, E., Castillejo, P., Ruíz, S., Koncz, C., del Pozo, J. C., et al. (2014). The TRANSPLANTA collection of Arabidopsis lines: a resource for functional analysis of transcription factors based on their conditional overexpression. Plant J. 77, 944-953. doi: 10.1111/tpj.12443

Cubas, P., Lauter, N., Doebley, J., and Coen, E. (1999). The TCP domain: motif found in proteins regulating plant growth and development. Plant J. 18, 215-222. doi: 10.1046/j.1365-313X.1999.00444.x

Danisman, S. (2016). TCP transcription factors at the interface between environmental challenges and the plant's growth responses. Front. Plant Sci. 7:1930. doi: 10.3389/fpls.2016.01930

Dhadi, S. R., Krom, N., and Ramakrishna, W. (2009). Genome-wide comparative analysis of putative bidirectional promoters from rice, Arabidopsis and Populus. Gene 429, 65-73. doi: 10.1016/j.gene.2008.09.034

Dhaka, N., Bhardwaj, V., Sharma, M. K., and Sharma, R. (2017). Evolving tale of TCPs: new paradigms and old lacunae. Front. Plant Sci. 8:479. doi: 10.3389/fpls. 2017.00479

Franco-Zorrilla, J. M., López-Vidriero, I., Carrasco, J. L., Godoy, M., Vera, P., and Solano, R. (2014). DNA-binding specificities of plant transcription factors, and their potential to define target genes. Proc. Natl. Acad. Sci. U.S.A. 111, 2367-2372. doi: 10.1073/pnas.1316278111

Garcia-Molina, A., Andrés-Colás, N., Perea-García, A., Del Valle-Tascón, S. Peñarrubia, L., and Puig, S. (2011). The intracellular Arabidopsis COPT5 transport protein is required for photosynthetic electron transport under severe copper deficiency. Plant J. 65, 848-860. doi: 10.1111/j.1365-313X.2010. 04472.x

Garcia-Molina, A., Andrés-Colás, N., Perea-García, A., Neumann, U., Dodani, S. C., Huijser, P., et al. (2013). The Arabidopsis COPT6 transport protein functions in copper distribution under copper-deficient conditions. Plant Cell Physiol. 54, 1378-1390. doi: 10.1093/pcp/pct088

Garcia-Molina, A., Xing, S., and Huijser, P. (2014). Functional characterisation of Arabidopsis SPL7 conserved protein domains suggests novel regulatory mechanisms in the $\mathrm{Cu}$ deficiency response. BMC Plant Biol. 14:231. doi: 10.1186/s12870-014-0231-5

Giraud, E., Ng, S., Carrie, C., Duncan, O., Low, J., Lee, C. P., et al. (2010). TCP transcription factors link the regulation of genes encoding mitochondrial 
proteins with the circadian clock in Arabidopsis thaliana. Plant Cell 22, 3921-3934. doi: 10.1105/tpc.110.074518

Guan, P., Ripoll, J., Wang, R., Vuong, L., Bailey-Steinitz, L. J., Ye, D., et al. (2017). Interacting TCP and NLP transcription factors control plant responses to nitrate availability. Proc. Natl. Acad. Sci. U.S.A. 114, 2419-2424. doi: 10.1073/ pnas. 1615676114

Guan, P., Wang, R., Nacry, P., Breton, G., Kay, S. A., Pruneda-Paz, J. L., et al. (2014). Nitrate foraging by Arabidopsis roots is mediated by the transcription factor TCP20 through the systemic signaling pathway. Proc. Natl. Acad. Sci. U.S.A. 111, 15267-15272. doi: 10.1073/pnas.1411375111

Harmer, S. L., Hogenesch, J. B., Straume, M., Chang, H. S., Han, B., Zhu, T., et al. (2000). Orchestrated transcription of key pathways in Arabidopsis by the circadian clock. Science 290, 2110-2113. doi: 10.1126/science.290.5499.2110

Hermans, C., Vuylsteke, M., Coppens, F., Craciun, A., Inzé, D., and Verbruggen, N. (2010). Early transcriptomic changes induced by magnesium deficiency in Arabidopsis thaliana reveal the alteration of circadian clock gene expression in roots and the triggering of abscisic acid-responsive genes. New Phytol. 187, 119-131. doi: 10.1111/j.1469-8137.2010.03258.x

Hirayama, T., Kieber, J. J., Hirayama, N., Kogan, M., Guzman, P., Nourizadeh, S., et al. (1999). RESPONSIVE-TO-ANTAGONIST1, a Menkes/Wilson diseaserelated copper transporter, is required for ethylene signaling in Arabidopsis. Cell 97, 383-393. doi: 10.1016/S0092-8674(00)80747-3

Hong, S., Kim, S. A., Guerinot, M. L., and McClung, C. R. (2013). Reciprocal interaction of the circadian clock with the iron homeostasis network in Arabidopsis. Plant Physiol. 161, 893-903. doi: 10.1104/pp.112.208603

Hong-Hermesdorf, A., Miethke, M., Gallaher, S. D., Kropat, J., Dodani, S. C., Chan, J., et al. (2014). Subcellular metal imaging identifies dynamic sites of $\mathrm{Cu}$ accumulation in Chlamydomonas. Nat. Chem. Biol. 10, 1034-1042. doi: $10.1038 /$ nchembio. 1662

Jefferson, R. A., Kavanagh, T. A., and Bevan, M. W. (1987). GUS fusions: betaglucuronidase as a sensitive and versatile gene fusion marker in higher plants. EMBO J. 6, 3901-3907.

Kampfenkel, K., Kushnir, S., Babiychuk, E., Inzé, D., and Van Montagu, M. (1995). Molecular characterization of a putative Arabidopsis thaliana copper transporter and its yeast homologue. J. Biol. Chem. 270, 28479-28486. doi: $10.1074 /$ jbc. 270.47 .28479

Kieffer, M., Master, V., Waites, R., and Davies, B. (2011). TCP14 and TCP15 affect internode length and leaf shape in Arabidopsis. Plant J. 68, 147-158. doi: 10.1111/j.1365-313X.2011.04674.x

Kim, H., Wu, X., and Lee, J. (2013). SLC31 (CTR) family of copper transporters in health and disease. Mol. Aspects Med. 34, 561-570. doi: 10.1016/j.mam.2012. 07.011

Klaumann, S., Nickolaus, S. D., Fürst, S. H., Starck, S., Schneider, S., Ekkehard Neuhaus, H., et al. (2011). The tonoplast copper transporter COPT5 acts as an exporter and is required for interorgan allocation of copper in Arabidopsis thaliana. New Phytol. 192, 393-404. doi: 10.1111/j.1469-8137.2011.03798.x

Kosugi, S., and Ohashi, Y. (2002). DNA binding and dimerization specificity and potential targets for the TCP protein family. Plant J. 30, 337-348. doi: 10.1046/ j.1365-313X.2002.01294.x

Krom, N., and Ramakrishna, W. (2008). Comparative analysis of divergent and convergent gene pairs and their expression patterns in rice, Arabidopsis, and Populus. Plant Physiol. 147, 1763-1773. doi: 10.1104/pp.108.122416

Li, S. (2015). The Arabidopsis thaliana TCP transcription factors: a broadening horizon beyond development. Plant Signal. Behav. 10:e1044192. doi: 10.1080/ 15592324.2015.1044192

Martín-Trillo, M., and Cubas, P. (2010). TCP genes: a family snapshot ten years later. Trends Plant Sci. 15, 31-39. doi: 10.1016/j.tplants.2009.11.003

Mitra, A., Han, J., Zhang, Z. J., and Mitra, A. (2009). The intergenic region of Arabidopsis thaliana cab1 and cab2 divergent genes functions as a bidirectional promoter. Planta 229, 1015-1022. doi: 10.1007/s00425-008-0859-1

Mockler, T. C., Michael, T. P., Priest, H. D., Shen, R., Sullivan, C. M., Givan, S. A., et al. (2007). The DIURNAL project: DIURNAL and circadian expression profiling, model-based pattern matching, and promoter analysis. Cold Spring Harb. Symp. Quant. Biol. 72, 353-363. doi: 10.1101/sqb.2007. 72.006

Mukhopadhyay, P., and Tyagi, A. K. (2015). OsTCP19 influences developmental and abiotic stress signaling by modulating ABI4-mediated pathways. Sci Rep. 5:9998. doi: 10.1038/srep09998
Nicolas, M., and Cubas, P. (2016). TCP factors: new kids on the signaling block. Curr. Opin. Plant Biol. 33, 33-41. doi: 10.1016/j.pbi.2016.05.006

Nohales, M. A., and Kay, S. A. (2016). Molecular mechanisms at the core of the plant circadian oscillator. Nat. Struct. Mol. Biol. 23, 1061-1069. doi: 10.1038/ nsmb.3327

Palatnik, J. F., Allen, E., Wu, X., Schommer, C., Schwab, R., Carrington, J. C., et al. (2003). Control of leaf morphogenesis by microRNAs. Nature 425, 257-263. doi: 10.1038/nature01958

Peñarrubia, L., Andrés-Colás, N., Moreno, J., and Puig, S. (2010). Regulation of copper transport in Arabidopsis thaliana: a biochemical oscillator? J. Biol. Inorg. Chem. 15, 29-36. doi: 10.1007/s00775-009-0591-8

Peñarrubia, L., Romero, P., Carrió-Seguí, A., Andrés-Bordería, A., Moreno, J., and Sanz, A. (2015). Temporal aspects of copper homeostasis and its crosstalk with hormones. Front. Plant Sci. 6:255. doi: 10.3389/fpls.2015.00255

Perea-García, A., Andrés-Bordería, A., Mayo de Andrés, S., Sanz, A., Davis, A. M., Davis, S. J., et al. (2016a). Modulation of copper deficiency responses by diurnal and circadian rhythms in Arabidopsis thaliana. J. Exp. Bot. 67, 391-403. doi: $10.1093 /$ jxb/erv474

Perea-García, A., Garcia-Molina, A., Andrés-Colás, N., Vera-Sirera, F., PérezAmador, M. A., Puig, S., et al. (2013). Arabidopsis copper transport protein COPT2 participates in the cross talk between iron deficiency responses and low-phosphate signaling. Plant Physiol. 162, 180-194. doi: 10.1104/pp.112. 212407

Perea-García, A., Sanz, A., Moreno, J., Andrés-Bordería, A., Mayo de Andrés, S., Davis, A. M., et al. (2016b). Daily rhythmicity of high affinity copper transport. Plant Signal. Behav. 11:e1140291. doi: 10.1080/15592324.2016. 1140291

Pilon-Smits, E. A., Garifullina, G. F., Abdel-Ghany, S., Kato, S., Mihara, H., Hale, K. L., et al. (2002). Characterization of a NifS-like chloroplast protein from Arabidopsis. Implications for its role in sulfur and selenium metabolism. Plant Physiol. 130, 1309-1318. doi: 10.1104/pp.102.010280

Pruneda-Paz, J. L., Breton, G., Para, A., and Kay, S. A. (2009). A functional genomics approach reveals $\mathrm{CHE}$ as a component of the Arabidopsis circadian clock. Science 323, 1481-1485. doi: 10.1126/science.1167206

Puig, S. (2014). Function and regulation of the plant COPT family of highaffinity copper transport proteins. Adv. Bot. 2014:476917. doi: 10.1155/2014/ 476917

Rae, T. D., Schmidt, P. J., Pufahl, R. A., Culotta, V. C., and O'Halloran, T. V. (1999). Undetectable intracellular free copper: the requirement of a copper chaperone for superoxide dismutase. Science 284, 805-808. doi: 10.1126/science.284. 5415.805

Ravet, K., and Pilon, M. (2013). Copper and iron homeostasis in plants: the challenges of oxidative stress. Antioxid. Redox Signal. 19, 919-932. doi: 10.1089/ ars.2012.5084

Rawat, R., Xu, Z.-F., Yao, K.-M., and Chye, M.-L. (2005). Identification of ciselements for ethylene and circadian regulation of the Solanum melongena gene encoding cysteine proteinase. Plant Mol. Biol. 57, 629-643. doi: 10.1007/ s11103-005-0954-7

Rodrigo-Moreno, A., Andrés-Colás, N., Poschenrieder, C., Gunsé, B., Peñarrubia, L., and Shabala, S. (2013). Calcium- and potassium-permeable plasma membrane transporters are activated by copper in Arabidopsis root tips: linking copper transport with cytosolic hydroxyl radical production. Plant Cell Environ. 36, 844-855. doi: 10.1111/pce.12020

Rogers, H. J., Bate, N., Combe, J., Sullivan, J., Sweetman, J., Swan, C., et al. (2001). Functional analysis of cis-regulatory elements within the promoter of the tobacco late pollen gene g10. Plant Mol. Biol. 45, 577-585. doi: 10.1023/A: 1010695226241

Rubio-Somoza, I., Zhou, C. M., Confraria, A., Martinho, C., von Born, P., and Baena-Gonzalez, E. (2014). Temporal control of leaf complexity by miRNA-regulated licensing of protein complexes. Curr. Biol. 24, 2714-2719. doi: 10.1016/j.cub.2014.09.058

Salomé, P. A., Oliva, M., Weigel, D., and Kramer, U. (2013). Circadian clock adjustment to plant iron status depends on chloroplast and phytochrome function. EMBO J. 32, 511-523. doi: 10.1038/emboj.2012.330

Sancenón, V., Puig, S., Mateu-Andrés, I., Dorcey, E., Thiele, D. J., and Peñarrubia, L. (2004). The Arabidopsis copper transporter COPT1 functions in root elongation and pollen development. J. Biol. Chem. 279, 15348-15355. doi: 10.1074/jbc.M313321200 
Sancenón, V., Puig, S., Mira, H., Thiele, D. J., and Peñarrubia, L. (2003). Identification of a copper transporter family in Arabidopsis thaliana. Plant Mol. Biol. 51, 577-587. doi: 10.1023/A:1022345507112

Seila, A. C., Calabrese, J. M., Levine, S. S., Yeo, G. W., Rahl, P. B., Flynn, R. A., et al. (2008). Divergent transcription from active promoters. Science 322, 1849-1851. doi: $10.1126 /$ science. 1162253

Takeda, T., Amano, K., Ohto, M.-a., Nakamura, K., Sato, S., Kato, T., et al. (2006). RNA interference of the Arabidopsis putative transcription factor TCP16 gene results in abortion of early pollen development. Plant Mol. Biol. 61, 165-177. doi: 10.1007/s11103-006-6265-9

Terzaghi, W. B., and Cashmore, A. R. (1995). Photomorphenesis: seeing the light in plant development. Curr. Biol. 5, 466-468. doi: 10.1016/S0960-9822(95) 00092-3

Uberti-Manassero, N. G., Coscueta, E. R., and Gonzalez, D. H. (2016). Expression of a repressor form of the Arabidopsis thaliana transcription factor TCP16 induces the formation of ectopic meristems. Plant Physiol. Biochem. 108, 57-62. doi: 10.1016/j.plaphy.2016.06.031

Viola, I. L., Camoirano, A., and Gonzalez, D. H. (2016). Redox-dependent modulation of anthocyanin biosynthesis by the TCP transcription factor TCP15 during exposure to high light intensity conditions in Arabidopsis. Plant Physiol. 170, 74-85. doi: 10.1104/pp.15.01016

Viola, I. L., Güttlein, L. N., and Gonzalez, D. H. (2013). Redox modulation of plant developmental regulators from the class I TCP transcription factor family. Plant Physiol. 162, 1434-1447. doi: 10.1104/pp.113. 216416

Viola, I. L., Reinheimer, R., Ripoll, R., Manassero, N. G., and Gonzalez, D. H. (2012). Determinants of the DNA binding specificity of class I and class II TCP transcription factors. J. Biol. Chem. 287, 347-356. doi: 10.1074/jbc.M111. 256271

Wakano, C., Byun, J. S., Di, L. J., and Gardner, K. (2012). The dual lives of bidirectional promoters. Biochim. Biophys. Acta 1819, 688-693. doi: 10.1016/ j.bbagrm.2012.02.006

Wang, H., Mao, Y., Yang, J., and He, Y. (2015). TCP24 modulates secondary cell wall thickening and anther endothecium development. Front. Plant. Sci. 6:436. doi: $10.3389 /$ fpls.2015.00436

Wang, H. Y., Klatte, M., Jakoby, M., Bäumlein, H., Weisshaar, B., and Bauer, P. (2007). Iron deficiency-mediated stress regulation of four subgroup Ib BHLH genes in Arabidopsis thaliana. Planta 226, 897-908. doi: 10.1007/s00425-0070535- $\mathrm{x}$
Wang, S.-t., Sun, X.-l., Hoshino, Y., Yu, Y., Jia, B., Sun, Z.-w., et al. (2014). MicroRNA319 positively regulates cold tolerance by targeting OsPCF6 and OsTCP21 in rice (Oryza sativa L.). PLoS One 9:e91357. doi: 10.1371/journal. pone.0091357

Weiss, D., and Ori, N. (2007). Mechanisms of cross talk between gibberellin and other hormones. Plant Physiol. 144, 1240-1246. doi: 10.1104/pp.107.100370

Welchen, E., and Gonzalez, D. H. (2006). Overrepresentation of elements recognized by TCP-domain transcription factors in the upstream regions of nuclear genes encoding components of the mitochondrial oxidative phosphorylation machinery. Plant Physiol. 141, 540-545. doi: 10.1104/pp.105. 075366

Wu, J. F., Tsai, H. L., Joanito, I., Wu, Y. C., Chang, C. W., Li, Y. H., et al. (2016). LWD-TCP complex activates the morning gene CCA1 in Arabidopsis. Nat. Commun. 7:13181. doi: 10.1038/ncomms13181

Yamasaki, H., Hayashi, M., Fukazawa, M., Kobayashi, Y., and Shikanai, T. (2009). SQUAMOSA promoter binding protein-like7 is a central regulator for copper homeostasis in Arabidopsis. Plant Cell 21, 347-361. doi: 10.1105/tpc.108.060137

Yan, J., Chia, J. C., Sheng, H., Jung, H. I., Zavodna, T. O., Zhang, L., et al. (2017). Arabidopsis pollen fertility requires the transcription factors CITF1 and SPL7 that regulate copper delivery to anthers and jasmonic acid synthesis. Plant Cell 29, 3012-3029. doi: 10.1105/tpc.17.00363

Zhang, H., Zhao, X., Li, J., Cai, H., Deng, X. W., and Li, L. (2014). MicroRNA408 is critical for the HY5-SPL7 gene network that mediates the coordinated response to light and copper. Plant Cell 26, 4933-4953. doi: 10.1105/tpc.114.127340

Zuo, J., Niu, Q.-W., and Chua, N.-H. (2000). An estrogen receptor-based transactivator XVE mediates highly inducible gene expression in transgenic plants. Plant J. 24, 265-273. doi: 10.1046/j.1365-313x.2000.00868.x

Conflict of Interest Statement: The authors declare that the research was conducted in the absence of any commercial or financial relationships that could be construed as a potential conflict of interest.

Copyright (C) 2018 Andrés-Colás, Carrió-Seguí, Abdel-Ghany, Pilon and Peñarrubia. This is an open-access article distributed under the terms of the Creative Commons Attribution License (CC BY). The use, distribution or reproduction in other forums is permitted, provided the original author(s) and the copyright owner(s) are credited and that the original publication in this journal is cited, in accordance with accepted academic practice. No use, distribution or reproduction is permitted which does not comply with these terms. 